\title{
Hydrologic response to multimodel climate output using a physically based model of groundwater/surface water interactions
}

\author{
M. Sulis, ${ }^{1}$ C. Paniconi, ${ }^{2}$ M. Marrocu, ${ }^{3}$ D. Huard,${ }^{4}$ and D. Chaumont ${ }^{4}$ \\ Received 20 April 2012; revised 11 October 2012; accepted 24 October 2012; published 13 December 2012.
}

[1] General circulation models (GCMs) are the primary instruments for obtaining projections of future global climate change. Outputs from GCMs, aided by dynamical and/or statistical downscaling techniques, have long been used to simulate changes in regional climate systems over wide spatiotemporal scales. Numerous studies have acknowledged the disagreements between the various GCMs and between the different downscaling methods designed to compensate for the mismatch between climate model output and the spatial scale at which hydrological models are applied. Very little is known, however, about the importance of these differences once they have been input or assimilated by a nonlinear hydrological model. This issue is investigated here at the catchment scale using a process-based model of integrated surface and subsurface hydrologic response driven by outputs from 12 members of a multimodel climate ensemble. The data set consists of daily values of precipitation and $\mathrm{min} /$ max temperatures obtained by combining four regional climate models and five GCMs. The regional scenarios were downscaled using a quantile scaling bias-correction technique. The hydrologic response was simulated for the $690 \mathrm{~km}^{2}$ des Anglais catchment in southwestern Quebec, Canada. The results show that different hydrological components (river discharge, aquifer recharge, and soil moisture storage) respond differently to precipitation and temperature anomalies in the multimodel climate output, with greater variability for annual discharge compared to recharge and soil moisture storage. We also find that runoff generation and extreme event-driven peak hydrograph flows are highly sensitive to any uncertainty in climate data. Finally, the results show the significant impact of changing sequences of rainy days on groundwater recharge fluxes and the influence of longer dry spells in modifying soil moisture spatial variability.

Citation: Sulis M., C. Paniconi, M. Marrocu, D. Huard, D. Chaumont (2012), Hydrologic response to multimodel climate output using a physically based model of groundwater/surface water interactions, Water Resour. Res., 48, W12510, doi:10.1029/2012WR012304.

\section{Introduction}

[2] There have been many studies in recent years examining impacts of climate change on water resources over a range of scales [e.g., Arora and Boer, 2001; Caballero et al., 2007; Maxwell and Kollet, 2008; Chiew et al., 2009; Ferguson and Maxwell, 2010; Brolsma et al., 2010] and the uncertainty in climate projections at global and regional scales [e.g., Giorgi and Raquel, 2000; Pan et al., 2001; Déqué et al., 2007; de Elía et al., 2008; Mujumdar and Ghosh, 2008; Murphy et al., 2004]. Because different

\footnotetext{
${ }^{1}$ Meteorological Institute, University of Bonn, Bonn, Germany.

${ }^{2}$ Institut National de la Recherche Scientifique-Centre Eau, Terre et Environnement (INRS-ETE), Université du Québec, Québec, Canada.

${ }^{3}$ Center for Advanced Studies, Research and Development in Sardinia (CRS4), Cagliari, Italy.

${ }^{4}$ Ouranos Consortium on Regional Climatology and Adaptation to Climate Change, Montreal, Canada.

Corresponding author: M. Sulis, Meteorological Institute, University of Bonn, Germany, Meckenheimer Alle 176, 53115, Bonn, Germany. (msulis@ uni-bonn.de)

C2012. American Geophysical Union. All Rights Reserved. 0043-1397/12/2012WR012304
}

climate models exhibit varying levels of performance over different regions and for different climatic variables, one way to study uncertainty is to consider results from multiple climate models. This multimodel ensemble approach combines information provided by a collection of different models of similar structure and complexity [Krishnamurti et al., 1999; Hagedorn et al., 2005; Luo et al., 2007; Haddeland et al., 2011]. An implicit assumption of this approach is that multiple models that encompass different process parameterizations and schemes lead to more consistent and reliable information by reducing the characteristic biases and uncertainties of any individual model [Knutti et al., 2010].

[3] To investigate the range of possible climate change impacts on available water resources at the catchment scale, the ensemble of projections can be widened further by including different greenhouse gas emission scenarios, by implementing different downscaling techniques, and by forcing one (or more) hydrological models with the resulting atmospheric forcing outputs. In this framework, Wilby and Harris [2006] used a water balance model (CATCHMOD) and a multiple linear regression model to explore uncertainty in future low flows for the River Thames. In that study, the ensemble was obtained by combining information from four general circulation models (GCMs), two 
emission scenarios, and two statistical downscaling techniques. Similarly, Manning et al. [2009] forced the CATCHMOD model with an ensemble of model integrations represented by 11 regional climate models (RCMs) and two GCMs. In this case, the regional climate data were further downscaled through a stochastic weather generator. Christensen and Lettenmaier [2007] forced the variable infiltration capacity macroscale hydrological model (which in turn forced the Colorado river reservoir model) with an ensemble of 11 downscaled GCM members for two emission scenarios. The aim of that study was to evaluate the influence of the streamflow variability on the water resources management system of the Colorado river basin. A multimodel approach was also used by Bastola et al. [2011] through the combination of multiple emission scenarios, GCMs, and conceptual rainfall-runoff models to quantify uncertainty in streamflow projections for four study basins in Ireland. J. Chen et al. [2011] considered the entire cascade of uncertainties with respect to different features of the hydrograph response (average, peak, and low flow values) for a Canadian watershed. In that study, the overall uncertainty was accounted for by combining results from an ensemble of six GCMs, five GCM initial conditions, two emission scenarios, four downscaling techniques, three hydrological model structures, and 10 sets of hydrological model parameters. Majone et al. [2012] analyzed in detail streamflow time series generated by a semidistributed hydrological model driven in turn by an ensemble of six RCMs. The focus of their work was to address water resources management for the Gállego river basin in Spain under uncertain future climate conditions. Recently, multiple climate model combinations have also been considered for quantifying uncertainty in future projections of subsurface water volumes and fluxes. For example, Goderniaux et al. [2009] used climate time series generated by six RCMs to force a detailed surface-subsurface coupled model to estimate groundwater reserves for a mesoscale basin in Belgium. Allen et al. [2010] investigated the variability in recharge fluxes simulated by a one-dimensional (1-D) model driven with climate time series downscaled from four GCMs. Eight GCM-RCM combinations downscaled using three statistical methods were used by Stoll et al. [2011] to illustrate the range of recharge fluxes and hydraulic head fluctuations projected by an integrated hydrological model.

[4] Although the previous studies presented strategies for obtaining reliable projections of water resources availability considering information from different climate models, they do not investigate in detail the significance of multimodel differences on the integrated and distributed hydrological response at the catchment scale. With studies to date focused on analyses of a single state variable (e.g., river discharge or aquifer recharge), the interdependence between hydrological components in propagating multimodel climate anomalies over different temporal scales has not been examined. In addition, there are other facets of multimodel climate outputs that have been given little attention, such as the influence of a changing precipitation distribution on the physical mechanisms controlling the catchment response, the importance of wet spell lengthening on the recharge response, and the effect of longer dry periods on soil moisture dynamics.

[5] In this context, we present an assessment of the propagation of uncertainties in climate change signals in a physically based surface-subsurface coupled hydrological model. The uncertainty originates from 12 ensemble members which are derived from combinations of four RCMs and five GCMs. The climate model simulations contain uncertainties associated to structural errors as well as natural variability in the climate system. The RCM scenarios were further downscaled using a quantile scaling bias-correction technique that, rather than applying a correction only to the mean, forces the cumulative distribution functions of the control simulations of daily temperature and precipitation to match the observed distributions. The same corrections were then applied to RCM time series for the future. The hydrologic response of the selected study site, the des Anglais catchment in southwestern Quebec, Canada, is highly dependent on the amount and timing of seasonal snow accumulation and melt [Sulis et al., 2011], and is thus vulnerable to climate changes in temperature and precipitation. The model used in this study, the catchment hydrology (CATHY) physically based groundwatersurface water model [Camporese et al., 2010], generates detailed output on surface and subsurface water volumes and is well suited to investigating the propagation of precipitation and temperature anomalies from multimodel ensemble members into river discharge, aquifer recharge, and soil storage response variables.

\section{Data and Methods}

\subsection{Study Site}

[6] The des Anglais river basin (Figure 1) has a drainage area of $690 \mathrm{~km}^{2}$ and an average discharge of $300 \times 10^{6} \mathrm{~m}^{3}$ $\mathrm{yr}^{-1}$ at its outlet. It is the largest subcatchment of the transboundary Chateauguay River watershed, and has an elevation range from 30 to $400 \mathrm{~m}$. Vegetation communities within the catchment consist of $47 \%$ cropland (mainly, corn and soy), $37 \%$ deciduous forest, and $16 \%$ coniferous forest [Lamontagne and Nastev, 2010]. The bedrock consists of Cambrian to Middle Ordovician sedimentary rock and is overlain by unconsolidated sediments of glacial and postglacial origin (Wisconsinan period and Champlain sea event). These sediments are in turn overlain by quaternary deposits of silty till, compact and dense at the base and reworked and more permeable above [Tremblay et al., 2010].

[7] The study area belongs to the Great Lakes and St. Lawrence climate region, characterized by a semihumid climate with cold winters and humid summers. The annual mean temperature is $6.3^{\circ} \mathrm{C}$, with monthly variations from $-10^{\circ} \mathrm{C}$ in January to $20^{\circ} \mathrm{C}$ in July (Environment Canada, Canadian Daily Climate Data, 2004, http://climate.weather office.ec.gc.ca) and frost conditions from mid-November to the end of March. The average annual precipitation is $958 \mathrm{~mm}$, relatively uniformly distributed within the watershed, with snowfall prevalent from December to March when temperatures are below $0^{\circ} \mathrm{C}$.

\subsection{Climate-Forcing Data}

[8] Climate projections of extreme temperature and total precipitation for past and future conditions are derived from two sources. Most of the ensemble members used are those provided by the North American Regional Climate Change Assessment Program (NARCCAP), which produces simulations generated by a set of RCMs on a common period and 


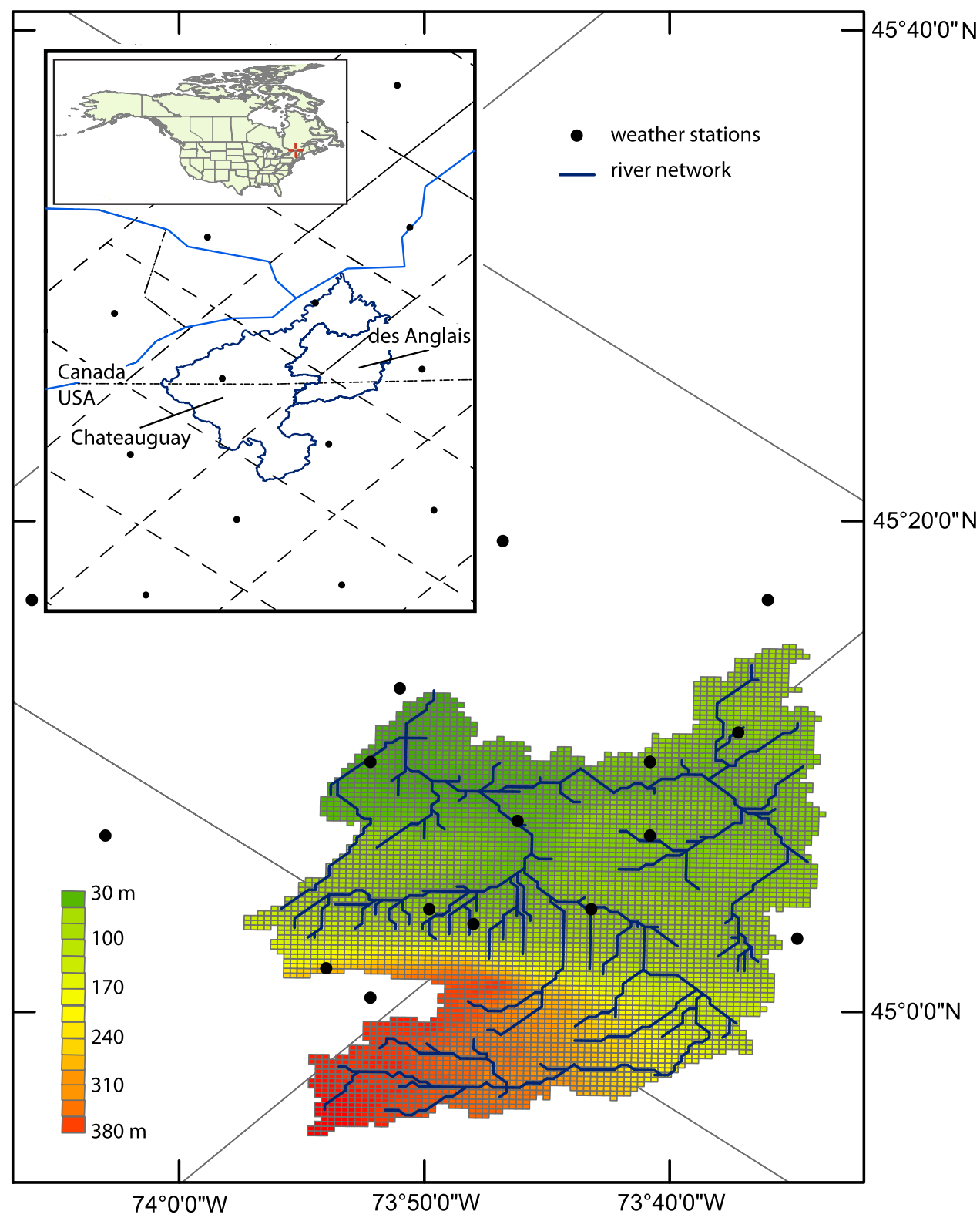

Figure 1. Topographic map of the des Anglais catchment showing the network of weather stations. The inset plot shows the centroids of the RCM grid with their Thiessen polygons and the location of the study area within the Chateauguay river basin.

domain [Mearns et al., 2009]. For the study site considered in this work, the NARCCAP archive provides data sets from four RCMs and four GCMs (the Canadian RCM (CRCM); the Met Office Hadley Centre's Hadley Regional Model 3 (HadRM3); the National Center for Atmospheric Research (NCAR)/Pennsylvania State University mesoscale model 5 MM5; the Abdus Salam International Center for Theoretical Physics' RCM Version 3 RegCM3; the Canadian Climate Centre CGCM3 model; the Geophysical Fluid Dynamics Laboratory (GFDL) CM model; the Hadley Centre HadCM3 model; and the NCAR CCSM3 model). In addition to the NARCCAP data set, we also considered simulations obtained by nesting the CRCM model [Music and Caya, 2007] with both the Meteo France CNRM-CM3 [Gibelin and Déqué, 2003] and Max-Planck Institut of
Meteorology ECHAM5 [Jungclaus et al., 2006] global models. The list of models, available past and future simulation periods, and RCM/GCM pairings is given in Tables 1 and 2. The simulations of past climate follow historical greenhouse gas and aerosol concentrations while the future simulations are based on concentrations from the SRES A2 scenario [Nakicenovic et al., 2000]. To facilitate the comparison of climate models, their outputs were regridded to a common spatial grid of about $50 \mathrm{~km}$ resolution (Figure 1) by using an inverse distance-weighted interpolation method that considers just the neighboring points whose grid cells overlap the catchment area. In addition, the same time slice, i.e., 1971-1995 for the past and 2041-2065 for the future, was used for all analyses. The comparison of simulated data (by the RCMs) with observations for the historical period 
Table 1. List of Climate Models

\begin{tabular}{|c|c|c|c|}
\hline Institution & $\mathrm{RCM}$ & GCM & Simulation Period \\
\hline Canadian Centre for Climate Modeling and Analysis, Canada & $\mathrm{CRCM}$ & CGCM & $1961-2000 / 2041-2070$ \\
\hline Max Planck Institute for Meteorology, Germany & & ECHAM5 & $1961-2000 / 2041-2070$ \\
\hline Météo France-Centre Nationale de Recherches Météorologiques, France & & CNRM-CM3 & $1961-2000 / 2041-2070$ \\
\hline International Center for Theoretical Physics, Italy & RegCM3 & & $1968-1995 / 2038-2065$ \\
\hline Hadley Center for Climate Prediction and Research, U. K. & HadRM3 & HadCM3 & $1968-2000 / 2038-2070$ \\
\hline GFDL, USA & & GFDL & 1971-2000/2041-2070 \\
\hline NCAR, USA & MM5I & CCSM & $1971-2000 / 2041-2070$ \\
\hline
\end{tabular}

was made based on daily data of total precipitation and extreme temperature from 19 Environment Canada stations located inside the RCM grid cells (Figure 1).

[9] Uncertainties in climate change predictions at regional scale stem from the greenhouse gas scenarios, from the use of different GCMs and/or RCMs (referred to as intermodel variability), and from the predictions themselves (different realizations of a given scenario with a given GCM, referred to as internal model variability or natural climate variability). The available multimodel data set provides a good opportunity to investigate the relative contributions of some of these sources of uncertainty and variability. Indeed, it is possible to evaluate the second and third sources by comparing (1) the climate change responses of the same RCM forced by different GCMs; (2) the responses of different RCMs all forced by common boundary data from a single GCM; and (3) the responses of the same RCM driven by five ensemble members representing different initial conditions of the same GCM (see Table 3). It is important to note that because sample sizes are rather small, these enable only an approximate comparison of uncertainties, and should be interpreted as descriptive rather than quantitative. That is, a more detailed analysis would require data from an experiment set wherein one (or more) RCMs have been forced by a larger and more representative sample of GCMs. Examples along this line are provided by Déqué et al. [2007] and Kaufman and Sain [2010].

[10] Figures 2 and 3 illustrate the relative seasonal variations between future and past model simulated values of mean air temperature and total precipitation. The results are grouped to demonstrate the different sensitivity to each source of uncertainty. In the case of temperature (Figure 2), the results show that the spread for each source

Table 2. IDs for the Climate Model Combinations Used in This Study

\begin{tabular}{lc}
\hline ID & Combination \\
\hline 1 & CRCM+CGCM(1) \\
2 & CRCM+CGCM(2) \\
3 & CRCM+CGCM(3) \\
4 & CRCM+CGCM(4) \\
5 & CRCM+CGCM(5) \\
6 & CRCM+CNRM-CM3 \\
7 & CRCM+ECHAM5 \\
8 & RegCM3+CGCM(4) \\
9 & HadRM3+HadCM3 \\
10 & RegCM3+GFDL \\
11 & CRCM+CCSM \\
12 & MM5I+CCSM \\
\hline
\end{tabular}

is larger during the winter and spring and is relatively small in the summer and fall. Figure 2 also indicates that in winter the uncertainty due to internal or natural climate variability is larger than that arising from the GCM and RCM formulations and is similar to that in the other seasons, with the exception of spring when GCM uncertainty can be substantial. RCM uncertainty remains fairly constant through the four seasons, and is somewhat smaller than the uncertainty due to natural climate variability and GCM formulation.

[11] In the case of total precipitation (Figure 3), the spread for each source of uncertainty is substantially larger than that found for temperature. This reflects the more complex physical processes and interactions involved in precipitation phenomena, leading to a higher level of natural variability and higher degrees of uncertainty in model parameterizations of precipitation. From Figure 3, it is also apparent that this larger spread leads to stronger intraannual variability, with summer variations having different magnitude and sign. Moreover, the three sources of uncertainty seem to contribute about equally through the seasons, with natural variability being somewhat less significant in the fall.

\subsection{Bias Correction Method}

[12] The multimodel data set described in the previous section provides the possibility to force a hydrological model with meteorological variables that have already been dynamically downscaled. However, even time series with a high spatial resolution are still biased. A variety of methods can be used to account for this systematic mismatch between observed and simulated climate variables over a considered control period [Anandhi et al., 2011; Stoll et al., 2011]. In this study, following the methodology of Mpelasoka and Chiew [2009], we implemented the daily translation method that has been shown to perform as well as more sophisticated statistical downscaling methods [Themeßl et al., 2011] and to be skillful in other hydrologic impact studies [Wood et al., 2004; Maurer and Hidalgo, 2008].

[13] In this transfer scheme, a quantile scaling technique is used to establish a relationship for the control period between observed and RCM-simulated daily values at the

Table 3. Summary of the Three Selected Sources of Uncertainty

\begin{tabular}{lc}
\hline Source of Uncertainty & Data Used \\
\hline $\begin{array}{l}\text { Internal or natural } \\
\text { variability }\end{array}$ & One RCM forced by different \\
GCM formulation & members of the same GCM \\
RCM formulation & One RCM forced by different GCMs \\
\hline
\end{tabular}



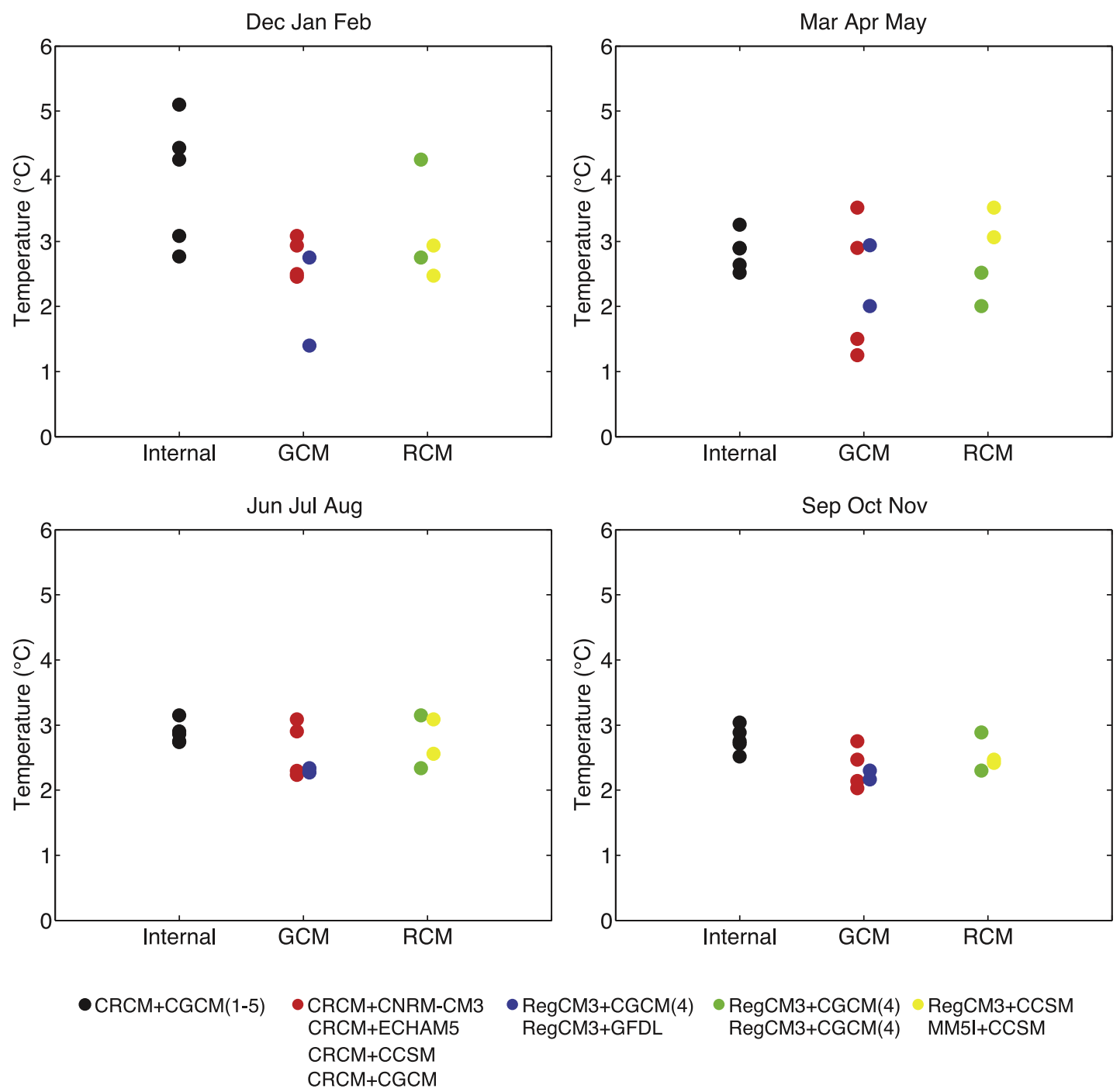

Figure 2. Projected climate change anomalies in seasonal mean temperature for the different sources of uncertainty described in Table 3. Values are computed as differences between 2041-2065 and 19711995 values.

different ranks/percentiles defined by interpolating directly from the empirical cumulative distribution function for each time series. Then, assuming that the biases are stationary in time, this relationship (additively for temperature and multiplicatively for precipitation) is separately applied for each of the 12 months to translate the future climate model data. For the case of precipitation, the quantile scaling technique reads as

$$
P_{i, j, k}^{f}=P_{i, j, k}^{\mathrm{mf}} \frac{P_{j, q}^{\mathrm{obs}}}{P_{j, q}^{\mathrm{mc}}} ; i=1,2, \ldots, 31 ; j=1,2, \ldots, 12 ; k=1,2, \ldots, 25
$$

where $P^{f}$ and $P^{\mathrm{mf}}$ are the future scaled and the future model projected precipitation values for day $i$, month $j$, and year $k$ and $P^{\mathrm{mc}}$ and $P^{\mathrm{obs}}$ are the past model simulated and observed precipitation values for month $j$ and quantile $q$. The advantage of this approach over the anomaly (delta) method is that the future series are independent of each other, thereby reflecting the differences in variability in future climate sequences. The series of an ensemble created using the anomaly method would all be based on the same observational time series, on which slightly different correction factors are applied. The main drawback of using a quantile scaling approach, on the other hand, is that it excludes a decrease in the number of dry days with respect to the control period.

\subsection{Climate Change Indicators}

[14] The projected signal as simulated by the bias-corrected (using equation (1)) multimodel ensemble data set was first evaluated in terms of the relative variation between future and past conditions of the monthly and yearly average values of mean temperature and total precipitation; the results are shown in Figures 4 and 5. In the case of temperature, the ensemble members predict a consistent increase of the yearly averaged mean temperature ranging from 2.0 to $3.2^{\circ} \mathrm{C}$. On a monthly basis, instead, slightly larger differences were found between the ensemble members, with some of them projecting 

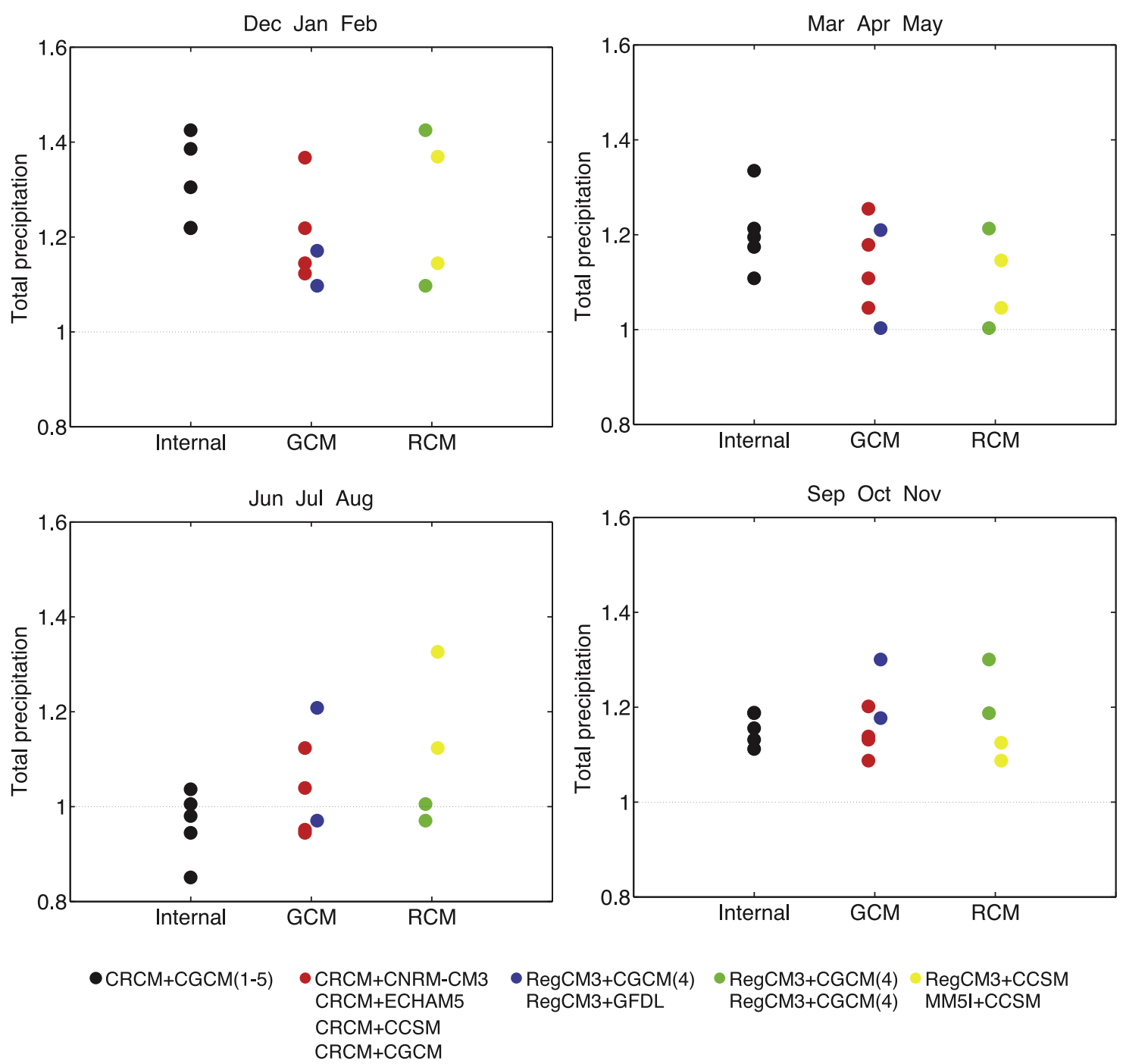

Figure 3. Projected climate change anomalies in seasonal mean precipitation for the different sources of uncertainty described in Table 3. Values are computed as ratios between 2041-2065 and 1971-1995 values.

a lower temperature increase. This is especially true in late winter and early spring for the case of CRCM+CNRM-CM3, CRCM+ECHAM5, and RegCM3+CGCM, and in late fall and early winter for RegCM3+GFDL and MM5I+CCSM. In the case of total precipitation, the ensemble members project a consistent increase in the yearly averaged values from $5 \%$ to $16 \%$. On a monthly scale, the differences in model projections vary from month to month, with the largest ones (in terms of magnitude and direction of the variation) found in late winter and summer; see for instance, the case of CRCM+CGCM(4) and CRCM+CCSM in February, and that of RegCM3+ CGCM and MM5I+CCSM in July.

[15] In addition to the assessment of the average values, two more indicators describing important facets of climate change, i.e., changes in annual and monthly extreme values of temperature and precipitation, were also calculated. These indicators, initially proposed by Baettig et al. [2007] for an assessment of climate change at a global scale, are used here to provide a quick assessment of the agreement or disagreement between future extreme model projections for the des Anglais river basin. The indicators are calculated by determining the probability of occurrence within the future projections of those events that, within the control period, have a given frequency (e.g., once in 20 years). Thus, the procedure consists in fitting a cumulative density function to the data of the control period and into those projected by the climate models. Then, the exceedance probability of the quantile corresponding to the 95th (and 5th) percentile of the control period is calculated under the future scenario. A sketch of the procedure, which is performed on a yearly and monthly basis for the mean temperature and the total precipitation, is shown in Figure 6. For the probability calculation, temperature data were assumed to be normally distributed, whereas precipitation data were assumed to be gamma distributed, with parameters evaluated using maximum likelihood estimates.

[16] In the case of temperature, values between 0 and 19 in Figure 7 express, relative to the control period, additional extreme hot years and months over a 20 -year future period. In the case of total precipitation (Figure 8), we calculated 


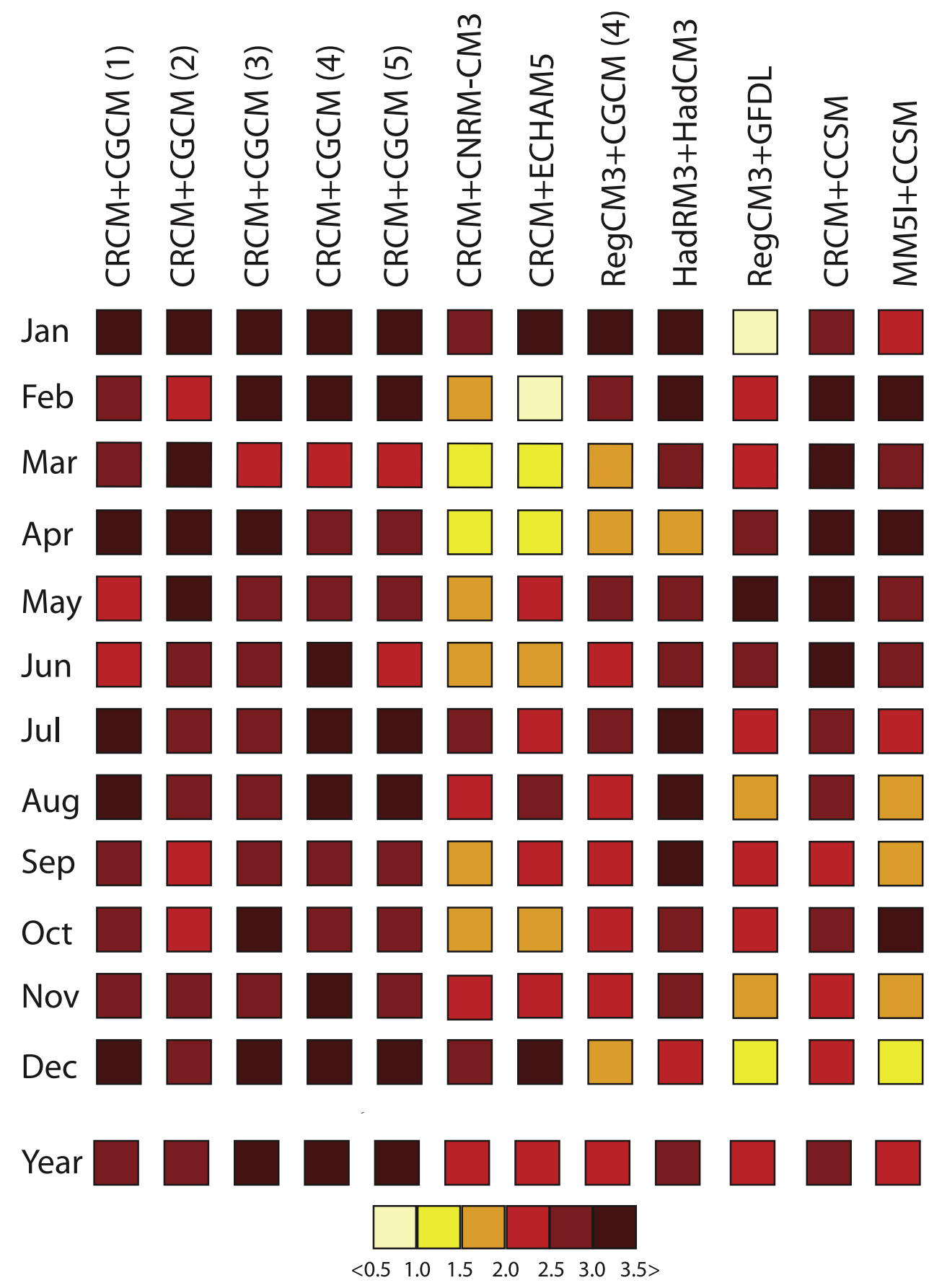

Figure 4. Difference between future and past-averaged values of mean temperature. Values are expressed in degree Celsius.

the future additional occurrence of both the driest and wettest years and months of the reference period (the low and high tails of the distribution shown in Figure 6).

[17] Figure 7 shows that annual mean temperature is predicted to experience a remarkable change. That is, the hottest year that occurs once in 20 years over the reference period will be the norm over the future period for all the ensemble members. In addition, for most of the climate models extreme monthly temperature events will undergo a noticeable increase. Despite agreement between models in terms of sign of the expected variation, Figure 7 also clearly shows sensible differences (for certain months) in the magnitude of predicted changes. For instance, a warm event that occurred once in 20 years in the reference period will occur over the future period from 2 (CRCM+ECHAM5) to 15.8 $(\mathrm{CRCM}+\mathrm{CGCM}(2))$ additional times in April, or from 2.1 $(\mathrm{CRCM}+\mathrm{CCSM})$ to $17.0(\mathrm{CRCM}+\mathrm{CGCM}(5))$ additional times in December. Differences between ensemble members seem to be damped in the summer months.

[18] Compared to temperature, variations in annual precipitation are less pronounced. In Figure 8, positive values indicate more wet events while negative values denote more 


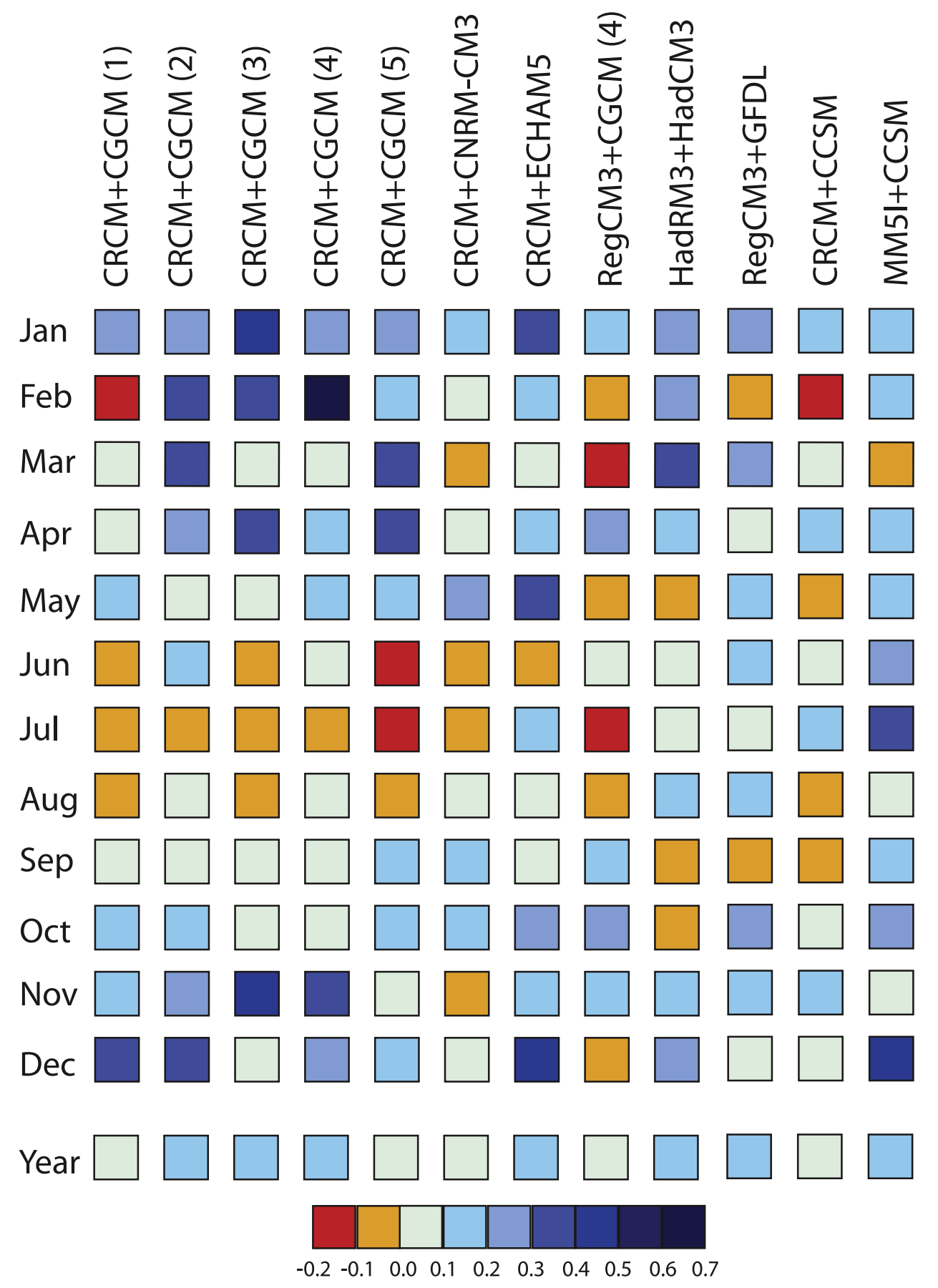

Figure 5. Relative fractional change between future and past-averaged values of total precipitation.

dry events. On a yearly basis, all models agree in predicting a wetter future climate, with the wettest year in 20 years of the reference period occurring up to eight additional times $(\mathrm{CRCM}+\mathrm{CGCM}(2))$ in the future period. An analysis on a monthly basis indicates that model projections show a general drying in summer (especially in July and August) and an increase in total precipitation in late fall and winter. In addition, Figure 8 shows that the precipitation change patterns vary in several months of the year for the different ensemble members. For instance, CRCM+CGCM(2) predicts the occurrence of five additional extremely wet events in March over 20 years, whereas for the same month
RegCM3+CGCM(4) predicts the occurrence of 4.5 additional extremely dry events.

[19] The use of indicators based on the calculation of mean and extreme values demonstrates that marked differences between ensemble members should be expected. These differences mainly concern the interannual variability of mean temperature and total precipitation. As demonstrated for other study areas, these differences may produce substantial impacts on the accumulation and melting dynamics of snow in winter and spring [Van Rheenan et al., 2004] and on the structure of storm and interstorm periods in summer and fall [Heinrich and Gobiet, 2011]. The 

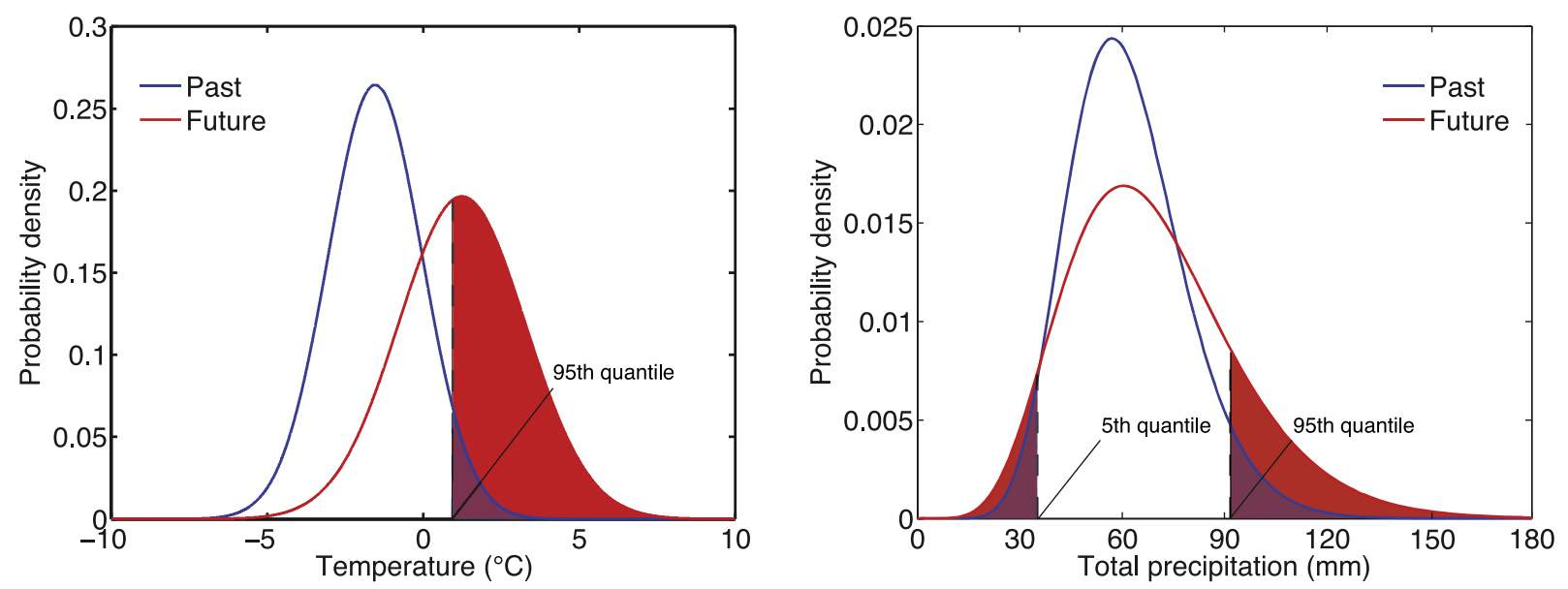

Figure 6. Illustration of the approach used to calculate the indicators of climate extremes for (left) temperature and (right) total precipitation.

indicators also show an occurrence of higher temperature periods along with more wet or dry events.

\subsection{Hydrological Model}

[20] CATHY is a coupled, physically based, spatially distributed model for surface-subsurface simulations [Camporese et al., 2010]. The model is based on resolution of a 1-D diffusion wave approximation of the Saint-Venant equation for overland and channel routing nested within a solver for the three-dimensional equation for subsurface flow in variably saturated porous media (i.e., Richards' equation). The routing scheme derives from a discretization of the kinematic wave equation based on the Muskingum-Cunge or matched artificial dispersivity method. Surface runoff is propagated through a 1-D drainage network of rivulets and channels automatically extracted by a digital elevation model (DEM) -based preprocessor and characterized using hydraulic geometry scaling relationships. The distinction between overland and channel flow regimes is made using threshold-type relationships based on, for instance, upstream drainage area criteria [Montgomery and Foufoula-Georgiou, 1993]. The subsurface solver is based on Galerkin finite elements in space, a weighted finite difference scheme in time, and linearization via Newton or Picard iteration [Paniconi and Putti, 1994].

[21] A boundary condition-switching procedure is used to partition potential (atmospheric) fluxes into actual fluxes across the land surface and changes in surface storage. This scheme resolves the coupling term in the CATHY equations that represents the interactions between surface and subsurface waters. The switching procedure distinguishes four possible states for a given surface node: ponded, saturated, unsaturated, and air dry. The distinction between ponded and saturated states is based on a threshold parameter that represents the minimum water depth before surface routing can occur (the threshold would be zero, for instance, for perfectly smooth surfaces and higher for increasingly rough surfaces). An air-dry state is the evaporative analog to rainfall saturation in triggering a switch from an atmospherecontrolled process (and a Neumann boundary condition in the model) to a soil-limited stage (and a Dirichlet condition).

[22] The model setup for the des Anglais catchment is described in detail in Sulis et al. [2011]. We used a constant lateral spatial discretization $(\Delta x=\Delta y)$ of $360 \mathrm{~m}$ and a vertical discretization $(\Delta z)$ of 10 layers that are progressively thicker from top to bottom. The parameterization of the surface hydraulic geometry (and scaling exponents) and of the subsurface hydraulic conductivity and other soil properties was achieved by calibrating and validating the model against discharge and groundwater level data over a period of 4 years.

\section{Results}

[23] The multimodel hydrological responses for the des Anglais river basin were obtained by running on a daily time scale the CATHY model with the past atmospheric data set (1971-1995) and the future data set (2041-2065), both obtained through the bias correction method described in the previous section. The analysis examines in detail, over several temporal scales and for each ensemble member indicated in Table 2, the propagation of precipitation and temperature anomalies into river discharge, aquifer recharge, and near-surface (0-90 cm depth) soil water-storage responses.

\subsection{River Discharge}

[24] The sensitivity of river discharge was assessed at the main outlet of the catchment. Figure 9 shows the relative annual changes in river discharge for each member of the ensemble. The changes vary from $-18 \%$ to $11 \%$ with 8 out of 12 members, predicting reduced runoff for the future period. These differences illustrate the complex hydrodynamic response at the catchment scale that results from temporal integration of climate variability from month to year. That is, although on an annual basis climate models experience broadly the same variations in terms of total precipitation and mean temperature (see Figures 4 and 5), their differences (especially, for precipitation) on an intraannual basis produce yearly variations of river discharge that are not consistent with each other. This is apparent, for instance, in comparing the CRCM+CGCM(4) and CRCM+ECHAM5 results; the increase in total precipitation occurring for both models with the same magnitude on a seasonal basis seems to be completely offset by a larger increase in temperature in the CRCM+CGCM(4) model. The differences between 


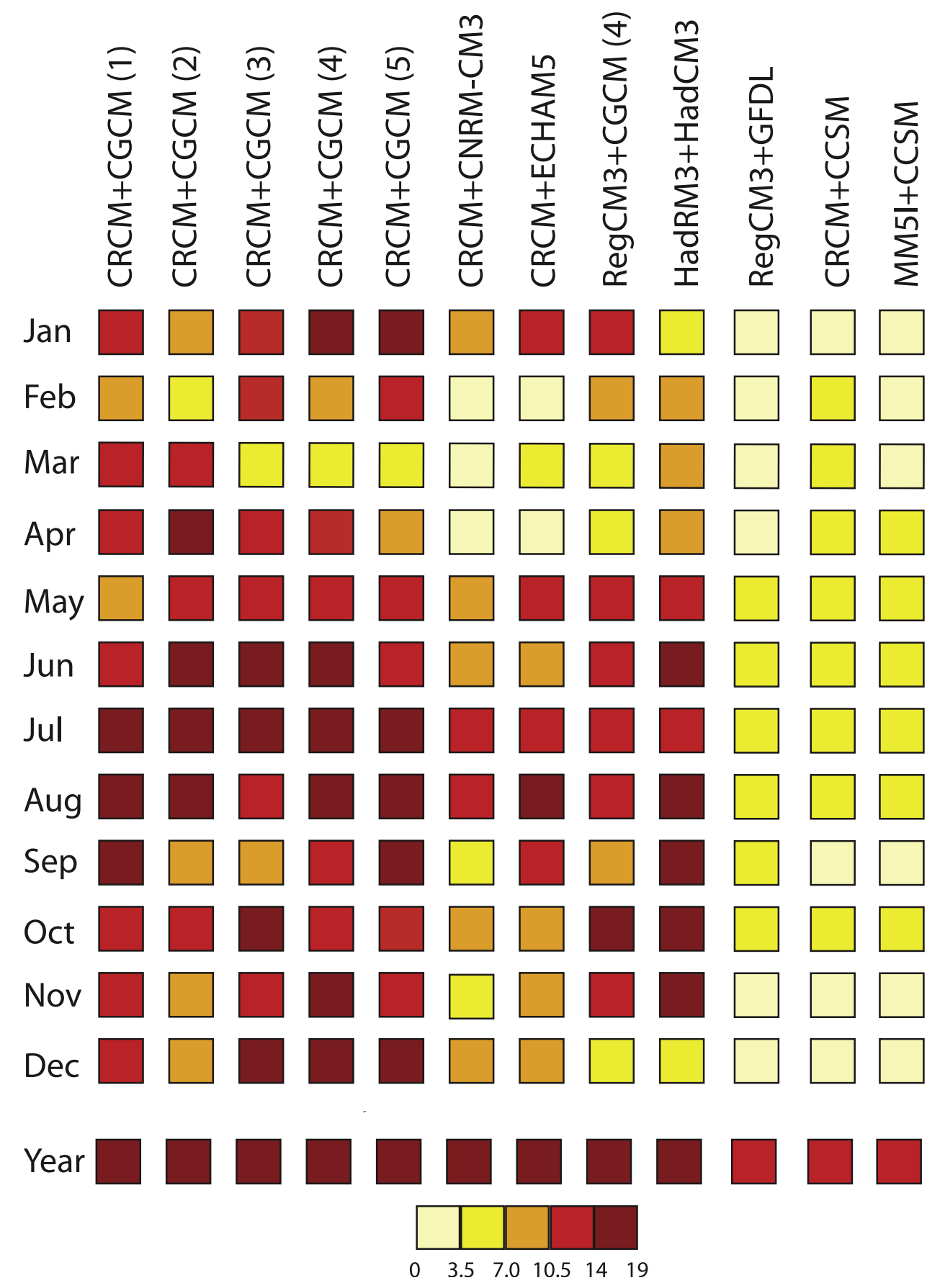

Figure 7. Temperature-related indicators of climate extremes. Values represent additional number of hottest months and years in 20 years.

simulation results in Figure 9 also illustrate the level of uncertainty in annual river discharge associated with natural climate variability (first five bars in the plot). This source of uncertainty is usually not considered very significant relative to other sources (such as interscenario and intermodel uncertainty), but the results obtained here show clearly that it can be quite important when the catchment response is strongly controlled by snow accumulation and melt [Deser et al., 2010].

[25] From an impacts perspective, changes in the temporal variability and extremes of the hydrological cycle may be more important than changes in mean behavior. We adopted a conventional and simple approach based on climate extreme indicators to provide useful information concerning changes in extremes. Figure 10 shows the percentage of days in the future climate with a discharge lower than the first decile of present-day daily discharges. For most of the members, a value between $10 \%$ and $25 \%$ was obtained, indicating that the frequency of occurrence of low flows in the future climate more than doubles for certain members. The sign of the changes in low-flow occurrence is consistent among the different members of the ensemble. The same 


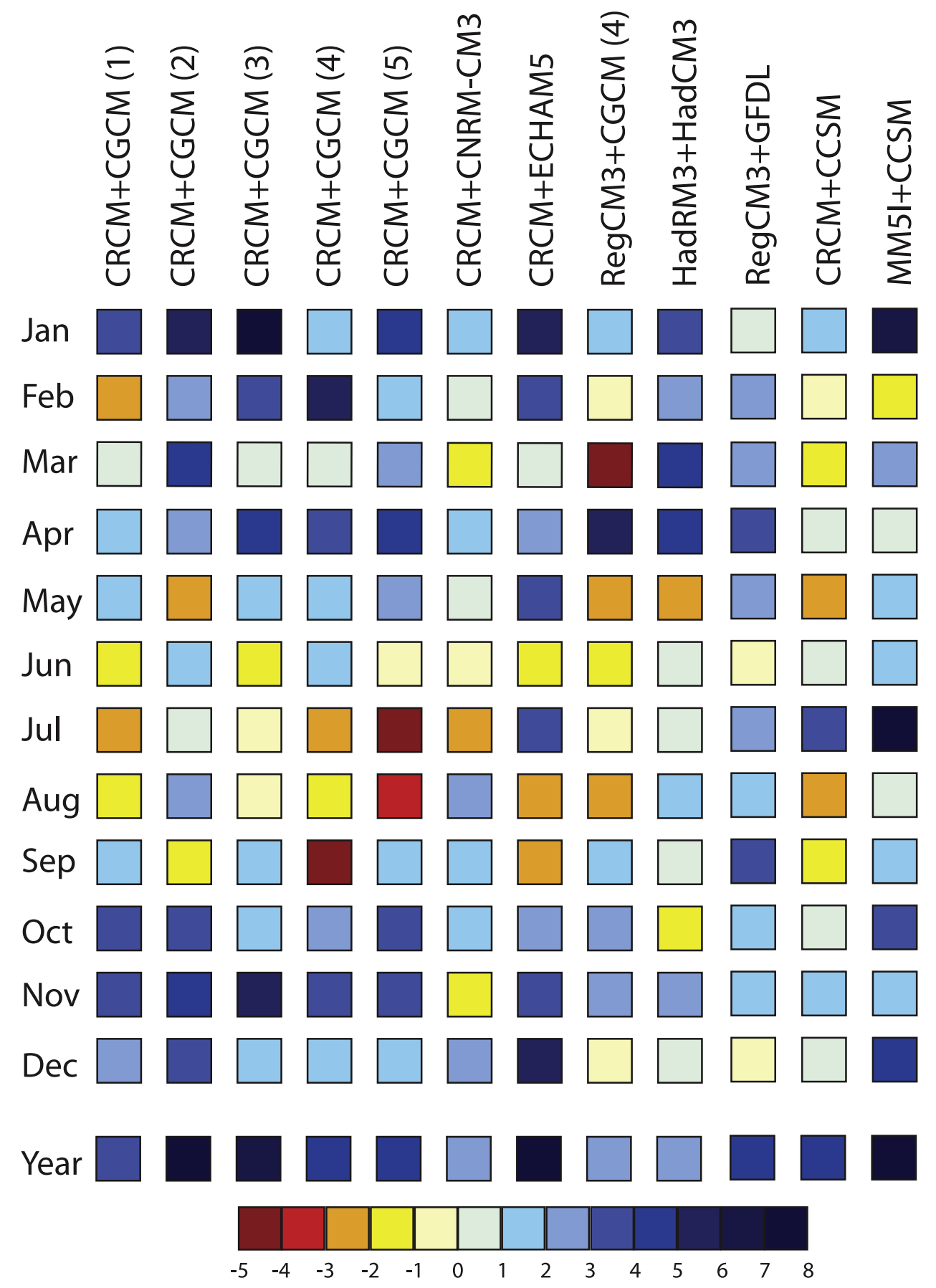

Figure 8. Precipitation-related indicators of climate extremes. Values represent additional number of wettest (positive) or driest (negative) months and years in 20 years.

trend was observed on a monthly basis (results not shown) over most of the year apart from a stronger increase in lowflow conditions in summer and late fall for the 4th, 5th, and 11 th ensemble members. Note that this behavior is consistent (especially for the fourth and fifth members) with the information portrayed in Figures 7 and 8 using the temperature and precipitation climate change indicators previously described.

[26] Figure 11 shows the ratio of the 90th percentile of daily discharge between future and past climate. The value of the 90th percentile increases for 4 of the 12 ensemble members. It can be seen that the sign of the changes in this upper tail of the discharge distribution are consistent with those in the annual total shown in Figure 9. That is, we should expect that climate change will not only simply induce a shift in the mean but also a modification in the shape of the discharge distribution. This explains why some combinations (2nd, 7th, 10th, and 12th members) exhibit both an increase in high flow intensity (Figure 11) and an increased occurrence of low-flow conditions (Figure 10).

[27] Additional insights on the hydrological impacts of climate change can be gleaned by examining the variation in the physical mechanisms that control the catchment 


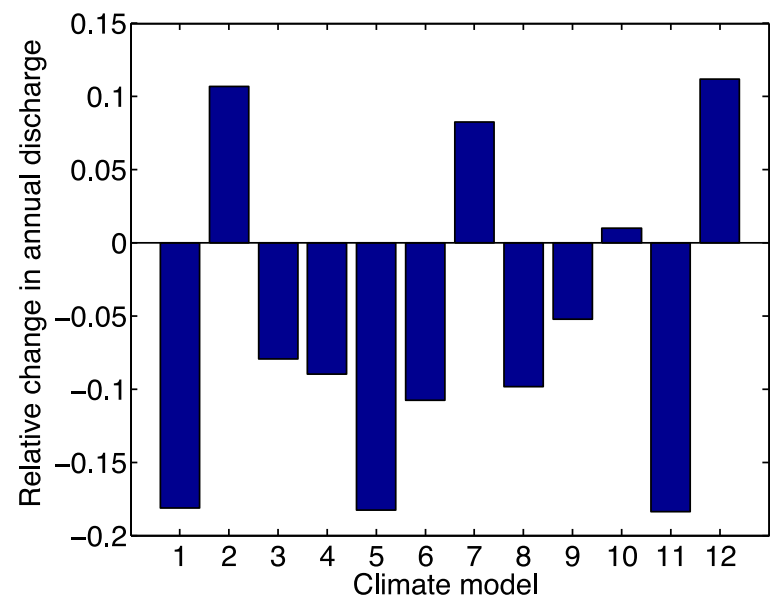

Figure 9. Relative change in annual river discharge between the 2041-2065 and 1971-1995 periods.

response. We examined the runoff generation process over the summer season (June to August), assessing the variation of total saturated area and its partitioning between the Dunne and Horton mechanisms. The analysis was performed on a daily basis by counting the number of times that each unsaturated surface node became saturated. The distinction between Dunne and Horton runoff is made by checking the vertical profile of pressure head. As shown in Figure 12, most of the models agree in predicting a decrease in total saturated area, most likely related to the decrease in net cumulative precipitation falling on the catchment. Larger differences between ensemble members are seen in predicting the occurrence of Dunne and Horton runoff events: differences in the former reflect differences in the monthly cumulative precipitation values, whereas differences in the latter follow more closely changes in the precipitation intensity. Indeed, as Hortonian runoff is triggered by precipitation events that are above a certain threshold (the saturated hydraulic conductivity of the soil at the land surface), the results shown in Figure 12 suggest that the ensemble climate

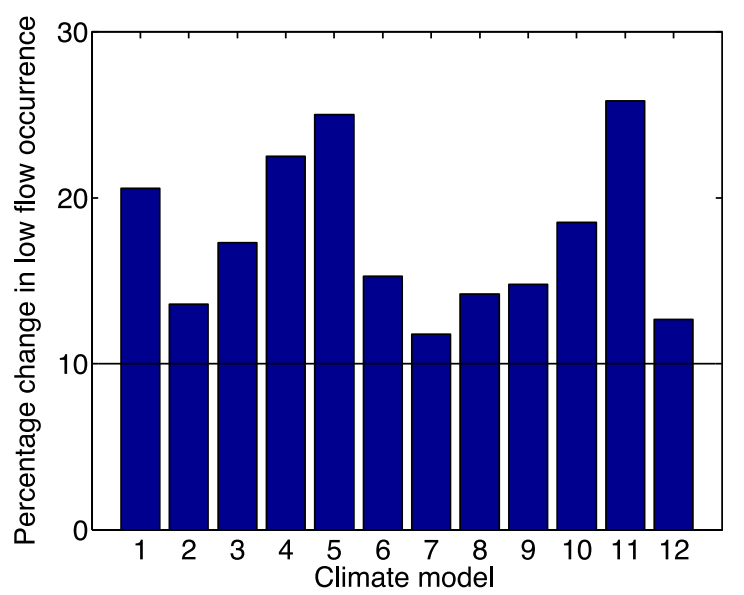

Figure 10. Percentage of days in the 2041-2065 period with a discharge lower than the first decile of daily discharge computed on the control period. models are projecting precipitation fields that have sensibly different distributions. The greater uncertainty in Horton and Dunne runoff patterns has direct implications for the frequency and strength of future floods, since overland flow is the primary component of most flood hydrographs.

\subsection{Recharge to the Aquifer}

[28] Recharge is computed in the CATHY model as the downward flux of water across the water table. Nodal recharge values were spatially cumulated and temporally averaged to obtain mean daily values for the past and future periods. These daily values were integrated on a yearly basis and then averaged for each of the past and future simulation periods. Figure 13 shows the relative change in average annual recharge for the 12 ensemble members. The percentage variations range from $4 \%$ for $\mathrm{CRCM}+\mathrm{CGCM}(4)$ to $-15 \%$ for HadRM $3+$ HadCM3 . It is apparent from this figure that the infiltration process and the travel time through the subsurface significantly dampen the precipitation signal. The ensemble members produce a smoother and more consistent recharge response compared to the river discharge response shown in Figure 9, with 11 out of 12 members projecting a decrease in annual groundwater recharge for the future despite the fact that 4 out of 12 members predicted an increase in annual total river discharge. Unlike the more rainfall event-driven stream discharge response, the intraannual variability in annual recharge is mainly driven by seasonal anomalies occurring during the recharge periods for the St. Lawrence climate region, specifically spring and fall.

[29] It is instructive to examine in more detail the differences between the two extreme members in Figure 13, $\mathrm{CRCM}+\mathrm{CGCM}(4)$ and HadRM3+HadCM3. For these two climate models, a difference of $5 \%$ in annual total precipitation translates to a $20 \%$ difference in annual aquifer recharge. From Figure 5, it is apparent that this effect is due to the combination of more snowfall in February (and hence an increase in snowmelt in early spring) for the first model and less rainfall in September and October for the second model. In addition, there are significant structural differences in the precipitation fields generated by the two

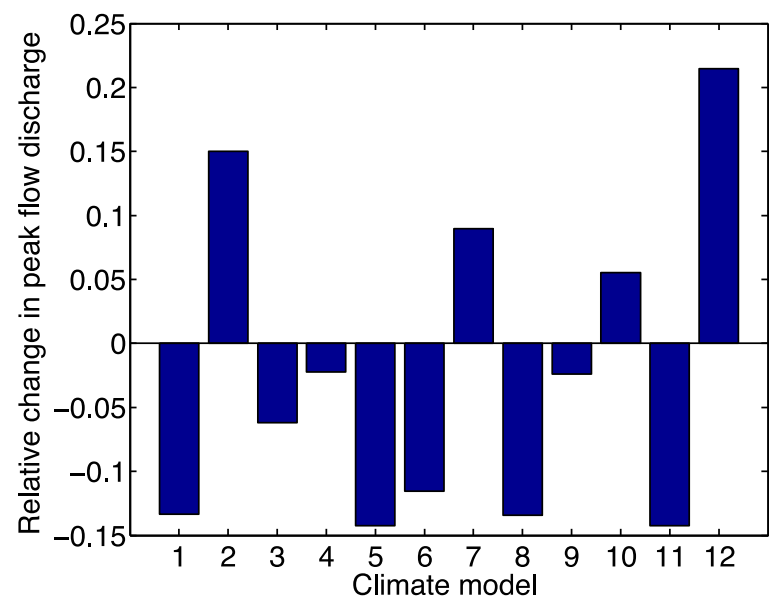

Figure 11. Relative change in the 90th quantile of daily river discharge between the 2041-2065 and 1971-1995 periods. 


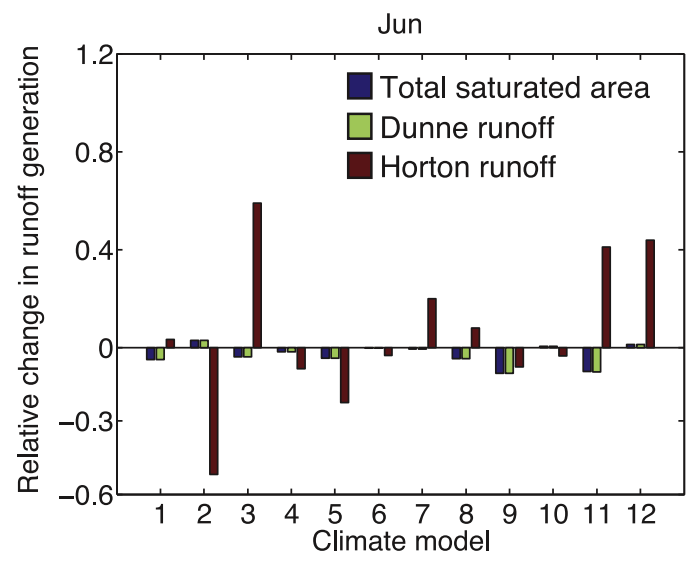

Jul

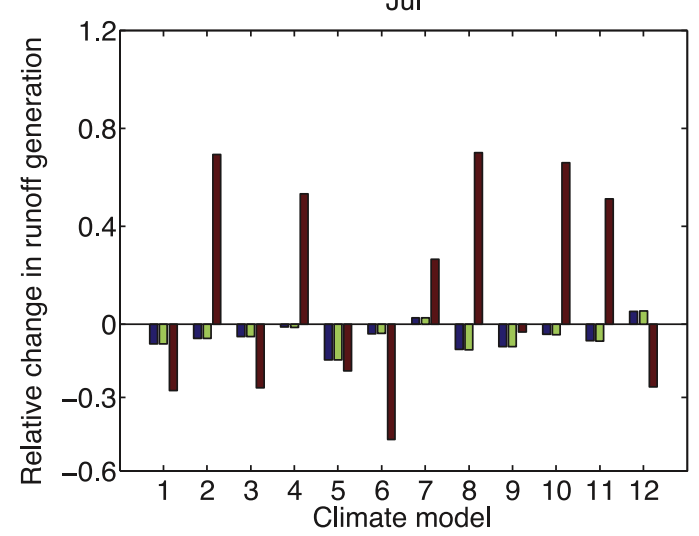

Aug

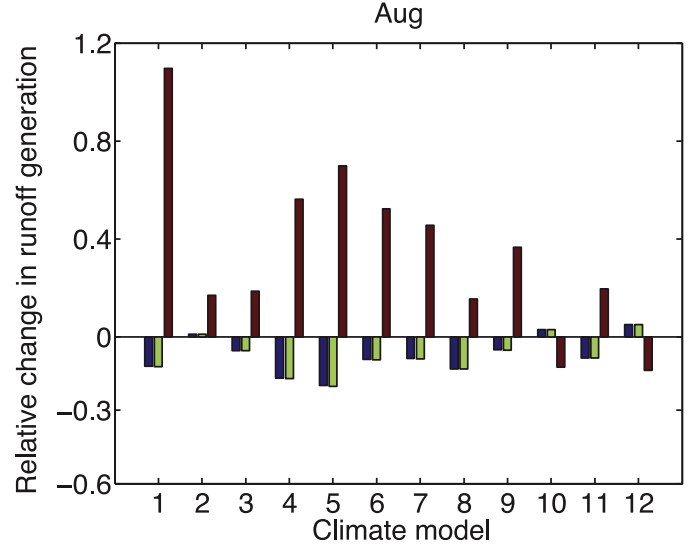

Figure 12. Relative change in average monthly fractions of Dunne and Horton runoff occurrence, as well as total saturated area, between the 2041-2065 and 1971-1995 summer periods.

models for late spring (April and May). Figure 14 shows that for these 2 months $\mathrm{CRCM}+\mathrm{CGCM}(4)$ projects an increase in the duration of wet spells, an important factor in enhancing groundwater recharge. The wet periods were quantified as consecutive days with significant precipitation $\left(\geq 1 \mathrm{~mm} \mathrm{~d}^{-1}\right)$. This threshold excludes very light precipitation and is commonly adopted in analyses of observed data to account for rain gauge accuracy [Klein-Tank and Konnen, 2003]. From Figure 14, it is clear that the CRCM+CGCM(4) model projects a lengthening of wet spells ( $\geq 5$ days) while

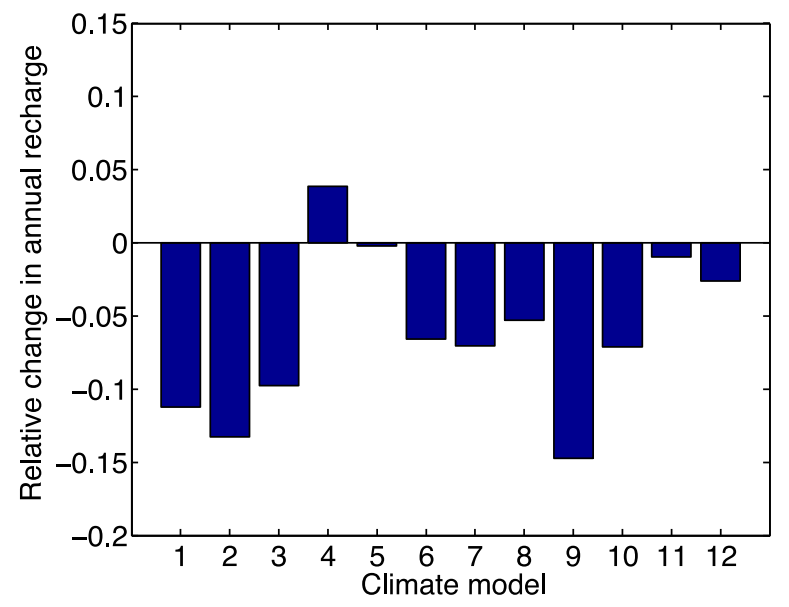

Figure 13. Relative change in annual aquifer recharge between the 2041-2065 and 1971-1995 periods.

the HadRM3 + HadCM3 model projects an increase of shortduration rain events ( $\leq 3$ days).

\subsection{Soil Water Storage}

[30] The multimodel soil water storage responses were evaluated at the surface (top $5 \mathrm{~cm}$ ) and at different soil depths $(5-15,15-45$, and $45-90 \mathrm{~cm})$. The daily values simulated over these four vertical sections corresponding to each land surface grid point were spatially aggregated and temporally averaged to obtain yearly values for the catchment. The relative variations between past and future climate simulations for the entire catchment were assessed and the results plotted in Figure 15. Compared to river discharge at the catchment outlet and aquifer recharge across the water table, the water storage responses are more consistent between past and future climates and between ensemble members. The percentage future/past variations range from $0.5 \%$ to $-5 \%$, and the differences between members are progressively damped as soil depth increases. The annual variations in the top layer of soil $(0-5 \mathrm{~cm})$ are mainly controlled by evaporation losses during the summer season (see also Sulis et al. [2011]) that are in turn driven by significant summer temperature variations (see Figure 4). It is also apparent from Figure 15 that soil moisture anomalies propagate differently across the soil layers for the different ensemble members. The CATHY model driven by the CRCM+ECHAM5 and MM5I+CCSM models (members 7 and 12 , respectively) predicts increased soil water storage for all layers, while the $\mathrm{CRCM}+\mathrm{CGCM}(2)$ case does so only for the 45-90 cm layer. All other simulations show a decrease in soil water storage, in all layers, for the future period. For the deepest soil layer $(45-90 \mathrm{~cm})$, the pattern of relative soil water storage changes for the ensemble of responses is quite similar to that obtained for the river discharge (compare Figure 9). This suggest that on an annual scale, precipitation anomalies between ensemble members are a dominant control on moisture variations in deeper soil layers. An opposite soil moisture trend is observed at a monthly scale during the summer months for the topsoil layer (Figure 16). In this case, the relative increase in total precipitation that occurs early in the year produces a relative increase in soil water storage for some members at the beginning of 

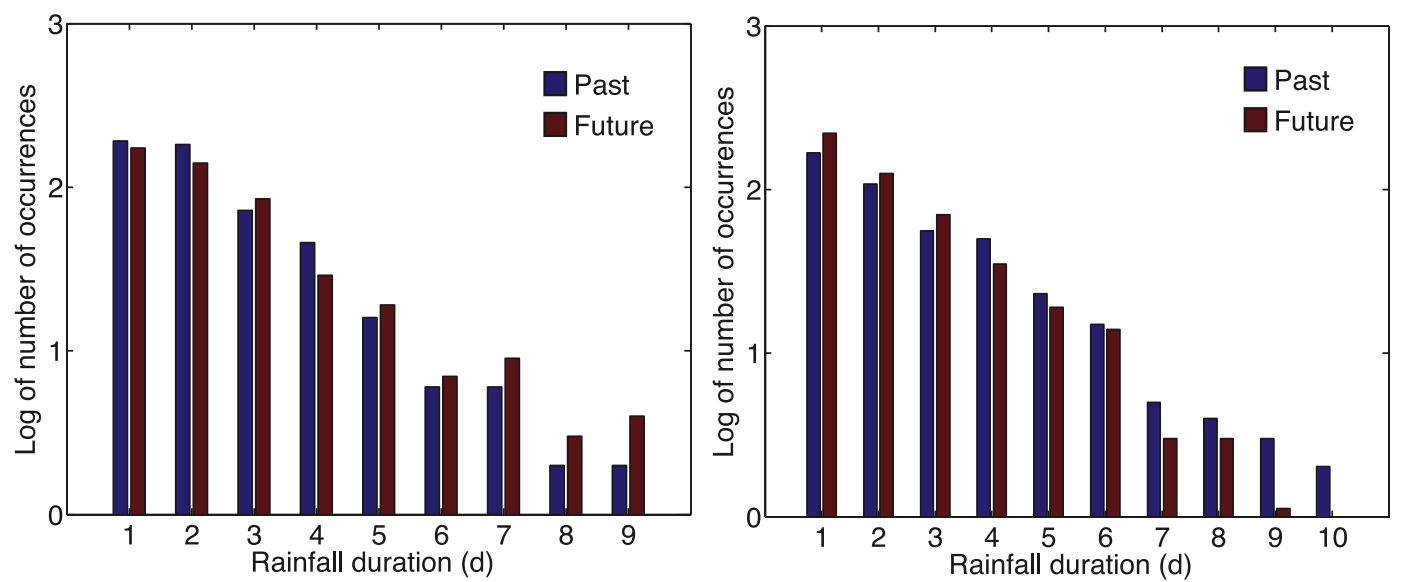

Figure 14. Frequency histograms of April and May wet period durations for past and future conditions for climate models (left) 4 (CRCM+CGCM(4)) and (right) 9 (HadRM3+HadCM3). Note that singleoccurrence events are log-plotted as 0.1 instead of 0 for graphical purposes.

the summer period that tends to disappear by late summer, and the relative variations between past and future periods become more significant as summer progresses. Thus, temperature anomalies between ensemble members this period of the year play a major role in soil water storage variations.

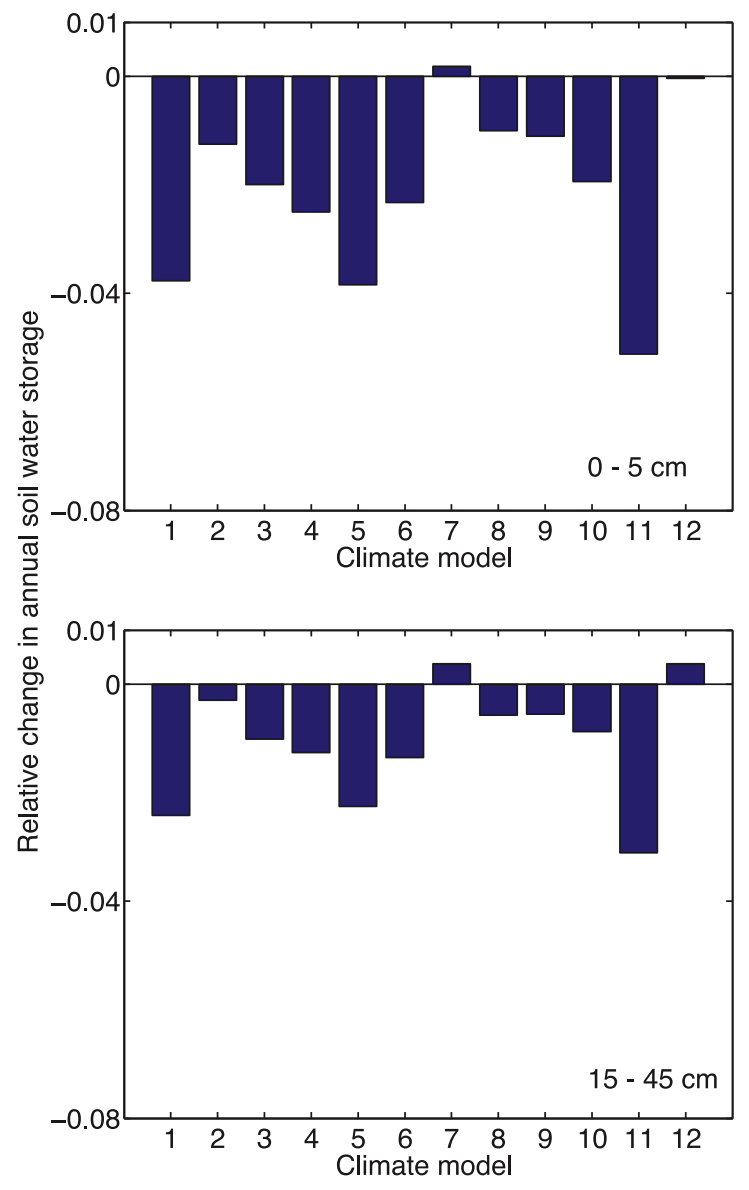

[31] For the top $5 \mathrm{~cm}$ layer, we also analyzed on a daily scale during the summer season the relation between the standard deviation and mean soil moisture content. This relationship is controlled by topographic features, soil attributes, and climate variations. The classic pattern discussed in the
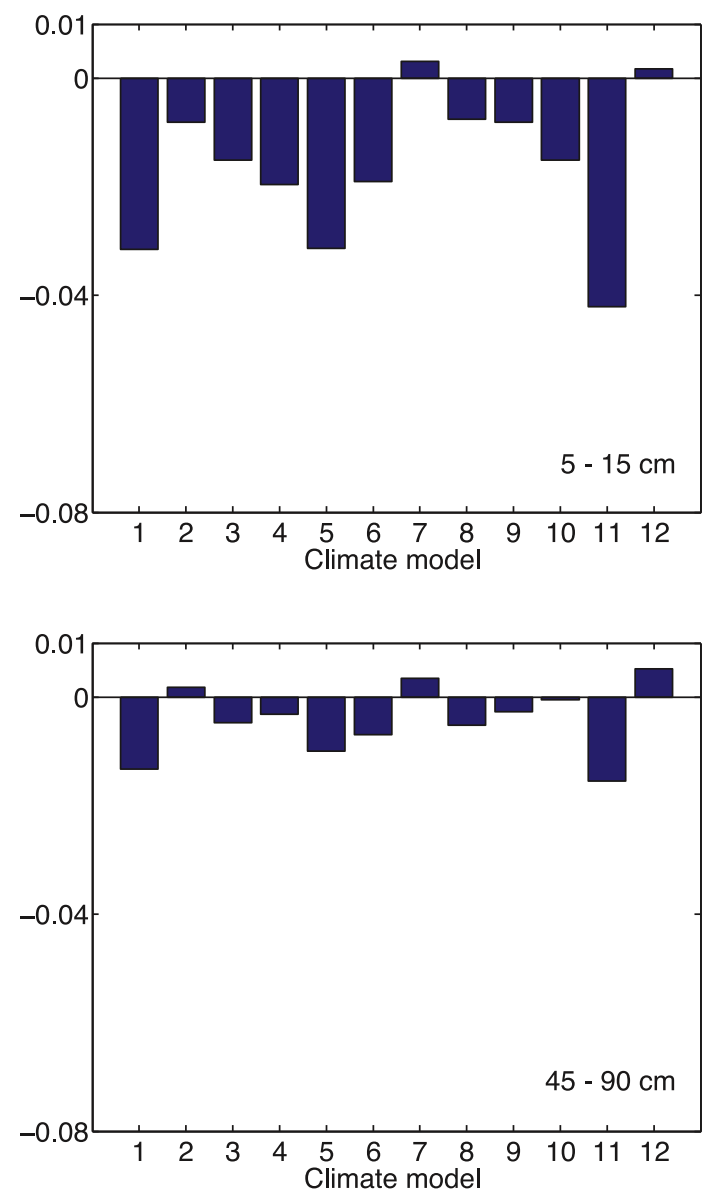

Figure 15. Relative change in annual soil water storage between the 2041-2065 and 1971-1995 periods. 

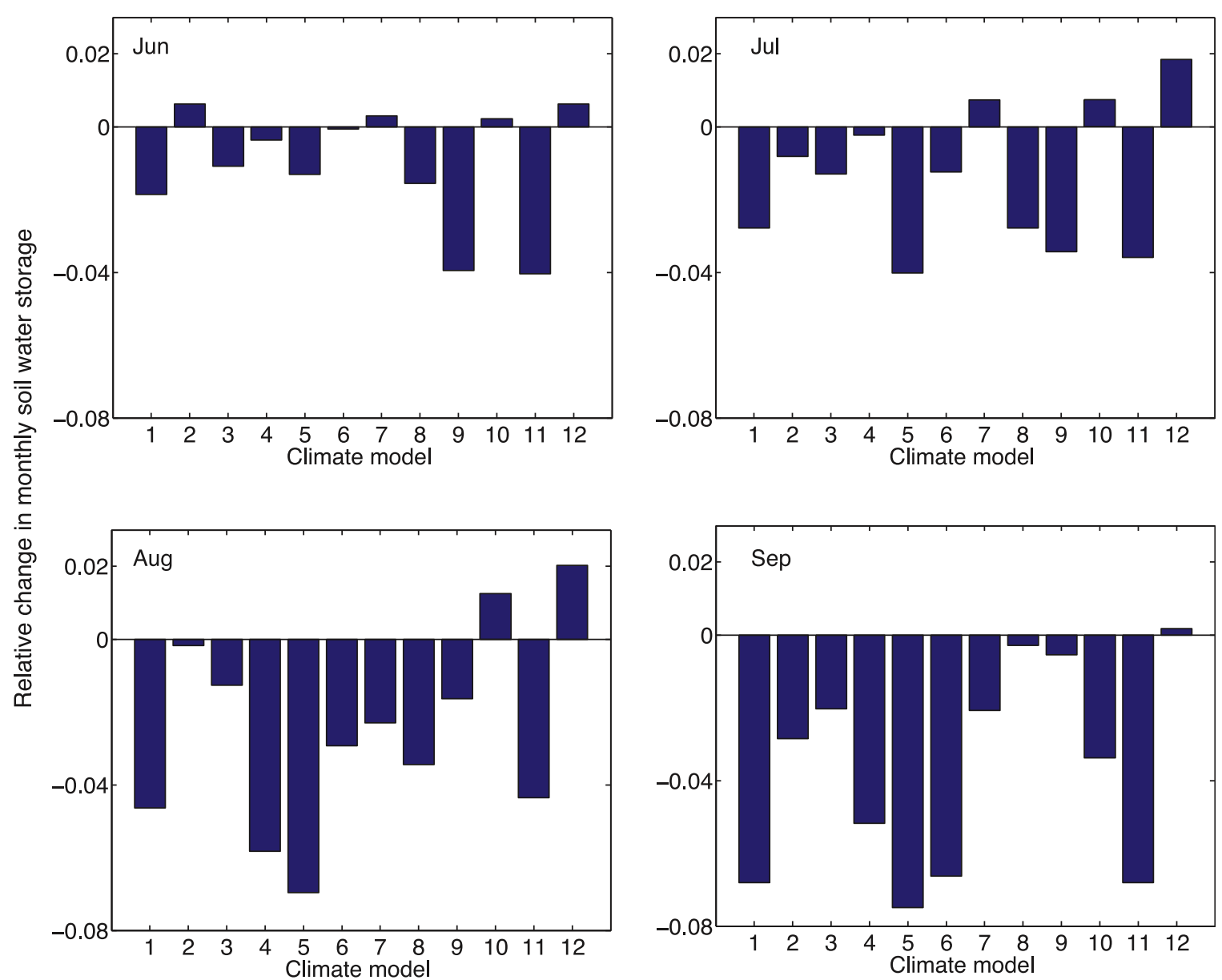

Figure 16. Relative change in monthly soil water storage for the summer season in the top $5 \mathrm{~cm}$ of soil between the 2041-2065 and 1971-1995 periods.

literature for temperate regions (e.g., Teuling et al. [2007]; Lawrence and Hornberger [2007]) can be recognized in Figure 17. That is, the standard deviation varies according to a convex-upward pattern for both past and future scenarios for each ensemble member, with an initial increase in spatial variability at lower moisture values followed by a strong decrease at higher values. These plots show that there are several members that attain a larger range of soil moisture values and that reach markedly drier conditions in the future daily values, in particular the CRCM+CGCM (1st, 2nd, and 5th members), the HadRM3+HadCM3 (9th member), and the CRCM+CCSM (11th member) combinations. Among these members, HadRM $3+$ HadCM 3 and CRCM+CCSM produce the most significant variations between future and past soil moisture dynamics, with a clear increase in soil moisture variability predicted for the future scenario. To investigate these differences in more detail, we compared for the two extreme cases, CRCM $+\mathrm{CGCM}(2)$ and $\mathrm{CRCM}+\mathrm{CCSM}$, the distribution of dry spells under past and future conditions. As shown in Figure 18, the CRCM+CCSM combination projects an increase in dry spells (i.e., a higher frequency of long periods without precipitation) compared to CRCM+CGCM(2). Under conditions of longer dry spells, near-surface soil moisture is controlled mainly by vertical evaporation fluxes that tend to decrease soil moisture connectivity and thereby increase its spatial variability.

\section{Conclusions}

[32] This paper has investigated uncertainty propagation of climate model output in catchment-scale hydrologic response. A multimodel framework with twelve different combinations of four RCMs and five GCMs was used in the analysis, and the outputs from this ensemble of climate model combinations, further downscaled by a quantile scaling bias-correction technique, were input to an integrated, distributed hydrological model. The quantile scaling technique forces the cumulative distribution functions of the control simulations of daily temperature and precipitation to match the observed distributions. The same corrections were then applied to the future time series. The response variables from the hydrological model that were examined include river discharge, aquifer recharge, and soil water storage. A study site in southwestern Quebec was selected for the simulations.

[33] The results show that the different hydrological state variables respond differently to the precipitation and temperature anomalies in the multimodel climate outputs and that those response variables that are most closely linked to changes in the distribution and extremes of precipitation events, whose evolution at the regional scale is still hard to predict, are characterized by a higher level of uncertainty. This was shown for instance in the prediction of high river 

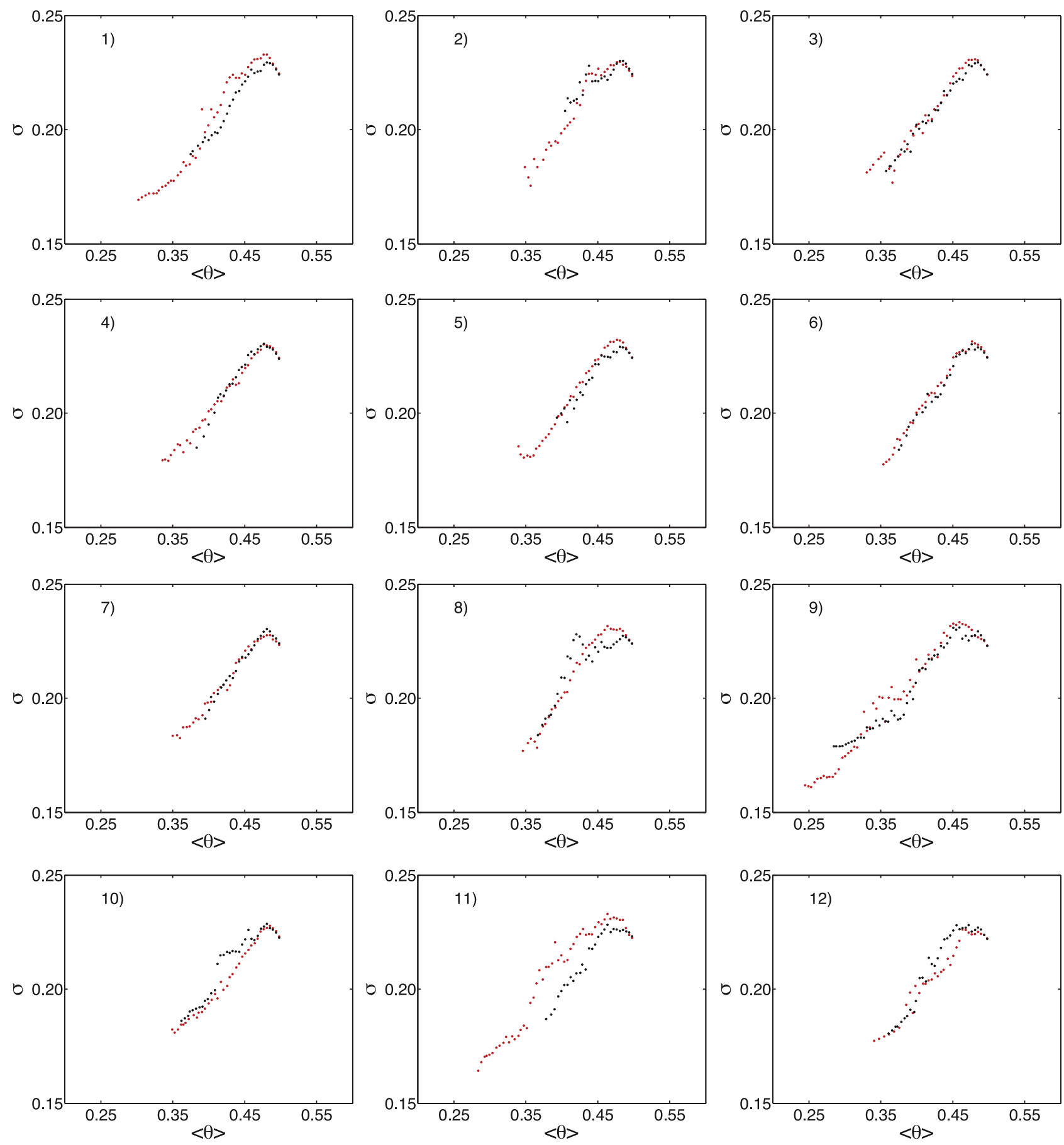

Figure 17. Relationship between daily mean soil moisture content $\langle\theta\rangle$ and its standard deviation $\sigma$ for the top $5 \mathrm{~cm}$ soil layer during the summer season for the 1971-1995 (black dots) and 2041-2065 (red dots) periods. The plot number corresponds to the climate model number within the ensemble.

flow conditions and in the analysis of runoff generation mechanisms. In this latter case, the projection of changes in precipitation frequency translates into variations in the occurrence of Hortonian runoff events that are indicators of a faster catchment response. On the other hand, hydrological response variables that are related more to mean precipitation values and temperature changes, in which more confidence is generally placed, are characterized to a certain extent by a lower uncertainty. This was evidenced by the smoother variations and greater consistency (between ensemble members and between past and future periods) in the hydrologic response of the catchment with respect to low flow conditions, soil water storage over different layers, and recharge fluxes to the aquifer. In the case of recharge, the results also show the large impact of changes in wet spell duration, where an inversion in the trend between short- and long-duration events, without a significant variation in total precipitation, led to divergent responses on a yearly scale 

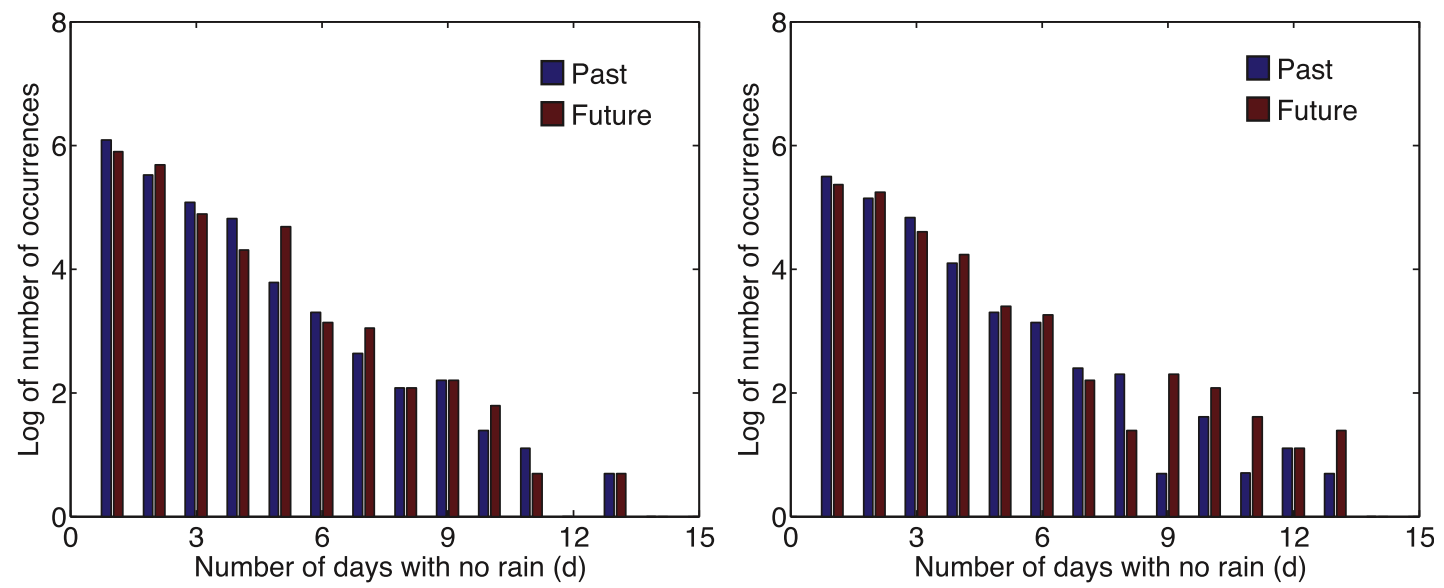

Figure 18. Frequency histograms of summer dry spells for past and future conditions for climate models (left) 2 (CRCM+CGCM(2)) and (right) 11 (CRCM+CCSM).

between the ensemble members. Moreover, through an analysis of dry spells during the summer season, it was found that longer dry periods lead to an increase in soil moisture spatial variability.

[34] It is important to note that despite the fact that the implementation of a bias correction method is a standard procedure in assessing climate change impacts, the assumptions underlying each technique (e.g., the correction functions apply to both current and future climate conditions) have important implications for the projected hydrological simulations [Teutschbein and Seibert, 2012; Ehret et al., 2012]. As such, the selected bias correction method adds another level of uncertainty, which may be of the same order of magnitude as that related to the choice of the climate or hydrological model [C. Chen et al., 2011; Hagemann et al., 2011].

[35] As final remarks, the large differences in the projected impacts on the hydrological response of the des Anglais catchment demonstrate that the use of projections from a single climate model ignores a significant source of uncertainty and that the use of a multimodel framework is essential in the definition of appropriate mitigation and adaptation strategies for this study region. In addition, the large range of hydrological responses underscores the highly nonlinear relationship between precipitation and temperature anomalies and the distributed and integrated physical variables that determine the catchment response. This suggests that multimodel techniques used in hydrological contexts can produce more reliable results if climate model weighting factors are based on both climate (temperature and precipitation) and hydrological (river discharge, groundwater levels, and soil moisture content) model performances.

[36] Acknowledgments. The authors acknowledge the financial support of the Ouranos Consortium and the Natural Sciences and Engineering Research Council of Canada (grant CRDPJ-319968-04), of the Ministre du Développement Économique, de l'Innovation et de 1'Exportation du Québec (grant PSR-SIIRI-434), of Seventh Framework Programme of the European Commission (project CLIMB, grant FP7-ENV-2009-1-244151), and of the SFB/TR32 project (Patterns in Soil-Vegetation-Atmosphere Systems: Monitoring, Modeling, and Data Assimilation) funded by the Deutsche Forschungsgemeinschaft (DFG). The CRCM data has been generated and supplied by Ouranos. The authors thank Blaise Gauvin-St-Denis from the Ouranos Consortium, who provided the data from the NARCCAP archive project. The authors also thank the reviewers for their helpful comments.

\section{References}

Allen, D. M., A. J. Cannon, M. W. Toews, and J. Scibek (2010), Variability in simulated recharge using different GCMs, Water Resour. Res., 46, W00F03, doi:10.1029/2009WR008932.

Anandhi, A. A. Frei, D. C. Pierson, E. M. Schneiderman, M. S. Zion, D. Lounsbury, and A. H. Matonse (2011), Examination of change factor methodologies for climate change impact assessment, Water Resour. Res., 47, W03501, doi:10.1029/2010WR009104.

Arora, V. K., and G. J. Boer (2001), Effects of simulated climate change on the hydrology of major river basins, J. Geophys. Res., 106(D4), 3335-3348. Baettig, M. B., M. Wild, and D. M. Imboden (2007), A climate change index: Where climate change may be most prominent in the 21 st century, Geophys. Res. Lett., 34, L01705, doi:10.1029/2006GL028159.

Bastola, S., C. Murphy, and J. Sweeney (2011), The role of hydrological modelling uncertainties in climate change impact assessments of Irish river catchments, Adv. Water Resour., 34(5), 562-576.

Brolsma, R. J., M. T. H. van Vliet, and M. F. P. Bierkens (2010), Climate change impact on a groundwater-influenced hillslope ecosystem, Water Resour. Res., 46, W11503, doi:10.1029/2009WR008782.

Caballero, Y., S. Voirin-Morel, F. Habets, J. Noilhan, P. LeMoigne, A. Lehenaff, and A. Boone (2007), Hydrological sensitivity of the AdourGaronne river basin to climate change, Water Resour. Res., 43, W07448, doi: 10.1029/2005WR004192.

Camporese, M., C. Paniconi, M. Putti, and S. Orlandini (2010), Surfacesubsurface flow modeling with path-based routing, boundary conditionbased coupling, and assimilation of multisource observation data, Water Resour. Res., 46, W02512, doi:10.1029/2008WR007536.

Chen, C., J. O. Haerter, S. Hagemann, and C. Piani (2011), On the contribution of statistical bias correction to the uncertainty in the projected hydrological cycle, Geophys. Res. Lett., 38, L20403, doi:10.1029/2011GL049318.

Chen, J., F. Brissette, A. Poulin, and R. Leconte (2011), Overall uncertainty study of the hydrological impacts of climate change for a Canadian watershed, Water Resour. Res., 47, W12509, doi:10.1029/2011WR010602.

Chiew, F. H., J. Teng, J. Vaze, D. A. Post, J. M. Perraud, D. G. C. Kirono, and N. R. Viney (2009), Estimating climate change impact on runoff across south-east Australia: Method, results and implications of modelling method, Water Resour. Res., 45, W10414, doi:10.1029/2008WR007338.

Christensen, N. S., and D. P. Lettenmaier (2007), A multimodel ensemble approach to assessment of climate change impacts on the hydrology and water resources of the Colorado River Basin, Hydrol. Earth Syst. Sci., 11, 1417-1434.

de Elía, R., D. Caya, H. Côté, A. Frigon, S. Biner, M. Giguère, D. Paquin, R. Harvey, and D. Plummer (2008), Evaluation of uncertainties in the CRCM-simulated North American climate, Clim. Dyn., 30, 113-132.

Déqué, M., D. P. Rowell, D. Lüthi, F. Giorgi, J. H. Christensen, B. Rockel, D. Jacob, E. Kjellström, M. de Castro, and B. van den Hurk (2007), An 
intercomparison of regional climate simulations for Europe: Assessing uncertainties in model projections, Clim. Change, 81(S1), 53-70.

Deser, C., A. Phillips, V. Bourdette, and H. Teng (2010), Uncertainty in climate change projections: The role of internal variability, Clim. Dyn., 38(3), 527-546.

Ehret, U., E. Zehe, V. Wulfmeyer, K. Warrach-Sagi, and J. Liebert (2012), Should we apply bias correction to global and regional climate model data?, Hydrol. Earth Syst. Sci., 16(9), 3391-3404.

Ferguson, I. M., and R. M. Maxwell (2010), The role of groundwater in watershed response and land surface feedbacks under climate change, Water Resour. Res., 46, W00F02, doi:10.1029/2009WR008616.

Gibelin, A.-L., and M. Déqué (2003), Antropogenic climate change over the Mediterranean region simulated by a global variable resolution model, Clim. Dyn., 20(4), 327-339.

Giorgi, F., and F. Raquel (2000), Evaluating uncertainties in the prediction of regional climate change, Geophys. Res. Lett., 27(9), 1295-1298.

Goderniaux, P., S. Brouyère, H. J. Fowler, S. Blenkinsop, R. Therrien, P. Orban, and A. Dassargues (2009), Large scale surface-subsurface hydrological model to assess climate change impacts on groundwater reserves, J. Hydrol., 373(1-2), 122-138.

Haddeland, I., et al. (2011), Multi-model estimate of the global terrestrial water balance: Setup and first results, J. Hydrometeorol., 12, 869-884, doi: 10.1175/2011JHM1324.1.

Hagedorn, R., F. J. Doblas-Reyes, and T. N. Palmer (2005), The rationale behind the success of multi-model ensembles in seasonal forecasting. Part I: Basic concept, Tellus, 57A, 219-233.

Hagemann, S., C. Chen, J. O. Haerter, J. Heinke, D. Gerten, and C. Piani (2011), Impact of a statistical bias correction on the projected hydrological changes obtained from three GCMs and two hydrology models, J. Hydrometeorol., 12(4), 556-578, doi:10.1175/2011JHM1336.1.

Heinrich, G., and A. Gobiet (2011), The future of dry and wet spells in Europe: A comprehensive study based on the ENSEMBLES regional climate models, Int. J. Climatol., 32, 1951-1970, doi:10.1002/joc.2421.

Jungclaus, J. H., M. Botzet, H. Haak, N. Keenlyside, J.-J. Luo, M. Latif, J. Marotzke, U. Mikolajewicz, and E. Roeckner (2006), Ocean circulation and tropical variability in the AOGCM ECHAM5/MPI-OM, $J$. Clim., 19(16), 3952-3972.

Kaufman, C. G., and S. R. Sain (2010), Bayesian functional ANOVA modeling using Gaussian process prior distributions, Bayes. Anal., 5(1), 123150 .

Klein-Tank, A. M., and G. P. Konnen (2003), Trends in indices of daily temperature and precipitation extremes in Europe, 1946-99, J. Clim., 16(22), 3665-3680.

Knutti, R., R. Furrer, C. Tebaldi, J. Cermak, and G. A. Meehl (2010), Challenges in combining projections from multiple climate models, J. Clim., 23(10), 2739-2758.

Krishnamurti, T. N., C. M. Kishtawal, and T. E. LaRow (1999), Improved weather and seasonal climate forecasts from multimodel superensemble, Science, 285, 1548-1559.

Lamontagne, C., and M. Nastev (2010), Survol hydrogéologique de l'aquifère transfrontalier du bassin versant de la rivière Châteauguay, Canada-États Unis, Can. Water Resour. J., 35, 359-376, doi:10.4296/cwrj3504359.

Lawrence, J. E., and G. M. Hornberger (2007), Soil moisture variability across climate zones, Geophys. Res. Lett., 34, L20402, doi:10.1029/ 2007 GL031382.

Luo, L., E. F. Wood, and M. Pan (2007), Bayesian merging of multiple climate model forecasts for seasonal hydrological predictions, J. Geophys. Res., 112, D10102, doi:10.1029/2006JD007655.

Majone, B., C. I. Bovolo, A. Bellin, S. Blenkinsop, and H. J. Fowler (2012), Modeling the impacts of future climate change on water resources for the Gállego river basin (Spain), Water Resour. Res., 48, W01512, doi:10.1029/ 2011WR010985.

Manning, L. J., J. W. Hall, H. J. Fowler, C. G. Kilsby, and C. Tebaldi (2009), Using probabilistic climate change information from a multimodel ensemble for water resources assessment, Water Resour. Res., 45, W11411, doi:10.1029/2007WR006674.
Maurer, E. P., and H. G. Hidalgo (2008), Utility of daily vs. monthly largescale climate data: An intercomparison of two statistical downscaling methods, Hydrol. Earth Syst. Sci., 12(2), 551-563.

Maxwell, R. M., and S. J. Kollet (2008), Interdependence of groundwater dynamics and land-energy feedbacks under climate change, Nat. Geosci., 1, 665-669, doi:10.1038/ngeo315.

Mearns, L. O., W. J. Gutowski, R. Jones, L.-Y. Leung, S. McGinnis, A. Nunes, and Y. Qian (2009), A regional climate change assessment program for North America, Eos Trans. AGU, 90(36), 311-312, doi:10.1029/ 2009EO360002.

Montgomery, D. R., and E. Foufoula-Georgiou (1993), Channel network source representation using digital elevation models, Water Resour. Res., 29(12), 3925-3934.

Mpelasoka, F. S., and F. H. Chiew (2009), Influence of rainfall scenario construction methods on runoff projections, J. Hydrometeor., 10, 11681183, doi:10.1175/2009JHM1045.1.

Mujumdar, P. P., and S. Ghosh (2008), Modeling GCM and scenario uncertainty using a possibilistic approach: Application to the Mahanadi River, India, Water Resour. Res., 44, W06407, doi:10.1029/2007WR006137.

Murphy, J. M., D. M. H. Sexton, D. N. Barnett, G. S. Jones, M. J. Webb, M. Collins, and D. Stainforth (2004), Quantification of modelling uncertainties in a large ensemble of climate change simulations, Nature, 430, 768-772, doi:10.1038/nature02770.1.

Music, B., and D. Caya (2007), Evaluation of the hydrological cycle over the Mississippi river basin as simulated by the Canadian Regional Climate Model (CRCM), J. Hydrometeor., 8(5), 969-988.

Nakicenovic, N., et al. (2000), Special Report on Emissions Scenarios, Cambridge Univ. Press, New York.

Pan, Z., J. H. Christensen, R. W. Arritt, W. J. Gutowsky, E. S. Takle, and F. Otieno (2001), Evaluation of uncertainties in regional climate change simulations, J. Geophys. Res., 106, D16, 735-751.

Paniconi, C., and M. Putti (1994), A comparison of Picard and Newton iteration in the numerical solution of multidimensional variably saturated flow problems, Water Resour. Res., 30(12), 3357-3374.

Van Rheenan, N. T., A. W. Wood, R. N. Palmer, and D. P. Lettenmaier (2004), Potential implications of PCM climate change scenarios for Sacramento-San Joaquin River basin hydrology and water resources, Clim. Change, 62, 257-281.

Stoll, S., H. J. Hendricks Franssen, M. Butts, and W. Kinzelbach (2011), Analysis of the impact of climate change on groundwater related hydrological fluxes: A multi-model approach including different downscaling methods, Hydrol. Earth Syst. Sci., 15(1), 21-38.

Sulis, M., C. Paniconi, C. Rivard, R. Harvey, and D. Chaumont (2011), Assessment of climate change impacts at the catchment scale with a detailed hydrological model of surface-subsurface interactions and comparison with a land surface model, Water Resour. Res., 47, W01513, doi: 10.1029/2010WR009167.

Teuling, A. J., F. Hupet, R. Uijlenhoet, and P. A. Troch (2007), Climate variability effects on spatial soil moisture dynamics, Geophys. Res. Lett., 34, L06406, doi:10.1029/2006GL029080.

Teutschbein, C., and J. Seibert (2012), Bias correction of regional climate model simulations for hydrological climate-change impacts studies: Review and evaluation of different methods, J. Hydrol., 456-457, 12-29.

Themeß1, M. J., A. Gobiet, and A. Leuprecht (2011), Empirical-statistical downscaling and error correction of daily precipitation from regional climate models, Int. J. Climatol., 31(10), 1530-1544.

Tremblay, T., M. Nastev, and M. Lamothe (2010), Grid-based hydrostratigraphic 3D modelling of the quaternary sequence in the Chateauguay River Watershed, Quebec, Can. Water Resour. J., 35, 377-398, doi:10.4296/ cwrj3504377.

Wilby, R. L., and I. Harris (2006), A framework for assessing uncertainties in climate change impacts: Low-flow scenarios for the River Thames, UK, Water Resour. Res., 42, W02419, doi:10.1029/2005WR004065.

Wood, A. W., L. R. Leung, V. Sridhar, and D. P. Lettenmaier (2004), Hydrologic implications of dynamical and statistical approaches to downscaling climate model outputs, Clim. Change, 62(1-3), 189-216. 